\title{
Research on the Dynamic Mechanical Properties and Constitutive Models of Steel Fiber Reinforced Concrete and Polypropylene Fiber Reinforced Concrete
}

\author{
Jie Huang, ${ }^{1}$ Yi Zhang, ${ }^{2}$ Yubin Tian $\mathbb{D}^{1},{ }^{1}$ Hengheng Xiao $\mathbb{D}^{1},{ }^{1}$ Jun Shi $\mathbb{D},{ }^{3}$ Jiyang Shen, ${ }^{1}$ \\ and Nianlin Zhang ${ }^{1}$ \\ ${ }^{1}$ Key Lab of Structures Dynamic Behavior and Control of the Ministry of Education, Harbin Institute of Technology, \\ Harbin 150090, China \\ ${ }^{2}$ Academy of Combat Support, Rocket Force University of Engineering, Xi'an 710025, China \\ ${ }^{3}$ School of Transportation Science and Engineering, Harbin Institute of Technology, Harbin 150090, China
}

Correspondence should be addressed to Yubin Tian; tianyubin@hit.edu.cn

Received 16 September 2019; Revised 10 December 2019; Accepted 3 January 2020; Published 11 February 2020

Academic Editor: Hayri Baytan Ozmen

Copyright (c) 2020 Jie Huang et al. This is an open access article distributed under the Creative Commons Attribution License, which permits unrestricted use, distribution, and reproduction in any medium, provided the original work is properly cited.

This paper presents the results of an experimental research designed to investigate the dynamic mechanical properties and constitutive model of fiber reinforced concrete (FRC), including steel fiber reinforced concrete (SFRC) and polypropylene fiber reinforced concrete (PFRC) under fast loading. Experimental results are achieved by using the electrohydraulic servo loading test method, implying that the dynamic mechanical properties of PFRC and SFRC, such as peak stress, peak strain, and toughness, are positively affected by strain rate. The experimental elastic modulus test results of FRC with different fiber contents indicate that the elastic modulus is positively affected by polypropylene or steel fibers and increases with the increment of fiber content. Finally, the experimental stress-strain curves obtained in the MTS electrohydraulic servo system test are fitted by a damage dynamic constitutive model of FRC. The good fitting with experimental results proves that the model could be appropriate to describe the dynamic mechanical properties of FRC.

\section{Introduction}

With the development of modern building structures, the defects of ordinary concrete, such as high self-weight, poor toughness, and low tensile strength can be seen as limits to its application and development in structure $[1,2]$. To tackle this problem, fiber reinforced concrete (FRC) has been a significant substitution for concrete and has attracted extensive attention in engineering field because of its excellent mechanical properties $[3,4]$. FRC is a kind of multiphase heterogeneous cementitious material with fibrous materials (e.g., steel, glass, carbon, polypropylene, etc.) as reinforcement and cement paste, mortar, or concrete as matrix $[5,6]$.

At present, there are two main kinds of FRC, respectively, high and low elastic modulus FRC corresponding to steel fiber reinforced concrete (SFRC) and polypropylene fiber reinforced concrete (PFRC). Many research studies on the physical and quasistatic mechanical properties of SFRC and PFRC have been carried out. Early studies indicated that the casting direction of steel fiber would affect the fiber distribution and orientation in concrete, which is closely related to the development of microcracks [7]. Then, many researchers have proved that after adding the appropriate amount of polypropylene or steel fibers, not only can the strength, durability, impact resistance, and bending fatigue property of concrete increase remarkably [8-11] but also the plastic shrinkage and crack propagation can be restrained obviously [12-14]. For example, Barros and Figueiras [8] carried out compressive tests on SFRC with steel fiber content of $0 \sim 60 \mathrm{~kg} / \mathrm{m}^{3}$ and obtained a recommended constitutive law for compressive stress and strain. They also pointed out that with the increase of fiber content, the 
bearing strength increased and the number and width of cracks decreased. Cao and Liu [12] investigated that the impact resistance of PFRC with $0.1 \% \sim 0.2 \%$ volume fraction could be increased by $4 \sim 6$ times. Then, the author investigated the performance of multidimensional FRC that mixed short steel fibers with long fibers to prepare graded fibers for experimental research. Test results proved that the fiber synergy effect of SFRC has a positive effect on the tensile strength of concrete and on the load and deformation capacity of concrete structures [15].

In practical applications of FRC, concrete structures have to inevitably withstand various dynamic loads, and this requires a higher impact resistance of concrete. Therefore, further studies of the dynamic behavior of FRC subjected to impact loading are necessary for its design and application. It has been proved by experimental results that the dynamic compressive strength and toughness of concrete matrix are remarkably enhanced by adding polypropylene fibers $[10,11]$. Since then, some experiments verified that FRC has an obvious strain rate effect and the dynamic compressive strength and the anti-impact properties of PFRC are obviously improved [16]. For instance, $\mathrm{Wu}$ et al. [17] revealed that concrete is a strain rate sensitive material and also found that failure stress, peak strain, and modulus of elasticity show significant strain rate hardening effect. Hu et al. [18] pointed out that under high strain rate loading, the failure strength of PFRC is roughly the same as that of plain concrete, but the toughness of PFRC is obviously improved. Afterwards, Xu et al. [19] conducted drop weight impact tests to study the dynamic compressive properties of FRC material with different types of fiber. The research results showed that the dynamic compressive strength of SFRC is 1.2 to 3 times higher than that of plain concrete. In addition, Li et al. [20] not only analyzed the influence of different dosage and aspect ratio on matrix toughness but also revised the coefficient of constitutive model under quasistatic uniaxial compression and obtained the toughness expression based on fiber content. It is very important to establish an accurate dynamic constitutive relationship for studying the mechanical properties of FRC. However, there are few studies on the dynamic constitutive relationship of FRC nowadays. On the basis of considering the damage of elastic modulus of concrete and neglecting the effect of strain rate on elastic modulus of concrete, Dong et al. [21] established a dynamic constitutive relationship. Shang [22] introduced the damage element into the generalized Maxwell constitutive element model, by considering that the concrete constitutive model consisted of elastic elements in parallel with two viscous elements and then in series with the damage element under fast loading. The above studies of the constitutive relations could show that the two constitutive relations are good proof of their experimental results, but they are quite different in the formulas of the dynamic constitutive model.

Generally, the current research studies on FRC mainly focus on static mechanical properties, but few research studies focus on the dynamic mechanical properties. In addition, research studies are mainly focused on SFRC, but few research studies are focused on other types of FRC.
Furthermore, it is a complex and difficult task to describe these dynamic mechanical properties perfectly and develop corresponding constitutive relations since concrete has extremely complex dynamic mechanical properties. However, few research studies on the dynamic constitutive relationship of FRC have been carried out, and there is no generally accepted dynamic constitutive model. It is evident that FRC is a strain rate sensitive material, but few people considered the effect of strain rate on the dynamic constitutive model. Therefore, this paper aims at providing further research on the dynamic mechanical properties (i.e., peak strain, peak stress, and toughness) of FRC subjected to compressive impact loading. A series of static elastic modulus tests and compression tests at different strain rates on FRC were performed. Moreover, this paper also analyzes which kind of fiber is more suitable for concrete engineering from the economic and performance aspects. Finally, on the basis of experimental results, the dynamic constitutive relationships of SFRC and PFRC are established correctly by analyzing the influence of fiber content and strain rate on the mechanical properties of concrete. This paper could be helpful to understand the dynamic mechanical properties and constitutive relationship of FRC more deeply, which also could promote the wider application of FRC in engineering.

\section{Experimental Program}

2.1. Materials and Mix Proportions. Two types of fiber were tested, namely, steel and polypropylene fibers, as illustrated in Figure 1. Steel fibers were wavy and characterised by length, width, and thickness equal to $32 \mathrm{~mm}, 1 \mathrm{~mm}$, and $0.6 \mathrm{~mm}$, respectively. The length of polypropylene fiber is $15 \mathrm{~mm}$. In addition, the tensile strength and elastic modulus of monofilament steel fiber and were about $1100 \mathrm{MPa}$ and $200 \mathrm{GPa}$, respectively, and those of monofilament polypropylene fiber were about $600 \mathrm{MPa}$ and $3.5 \mathrm{GPa}$, respectively. Coarse aggregates were granite gravel, and the particle size ranged from $10 \mathrm{~mm}$ to $20 \mathrm{~mm}$. Fine aggregates were medium sand, and the particle size ranged from $0.35 \mathrm{~mm}$ to $0.5 \mathrm{~mm}$. The compressive strength and elastic modulus of concrete were $30 \mathrm{MPa}$ and $30 \mathrm{GPa}$, respectively. Moreover, the proportions of the mixture are shown in are shown in Table 1.

2.2. Preparation of Specimens. According to Chinese Standard [23], the cylindrical specimens of $210 \mathrm{~mm}$ length and $105 \mathrm{~mm}$ diameter were fabricated for compressive strength tests at different strain rates. Besides, the test mould was made of plastic pipes with an inner diameter of $105 \mathrm{~mm}$ (wall thickness of $5 \mathrm{~mm}$ ) and a length of $210 \mathrm{~mm}$. Details of cylindrical specimens are shown in Table 2.

Prism specimens were employed for analyzing the variation of FRC's elastic modulus with different fiber contents. Herein, the size of prism is $100 \mathrm{~mm}$ (length) $\times$ $100 \mathrm{~mm}$ (width) $\times 300 \mathrm{~mm}$ (height), which used steel mould. The flatness of the specimens manufactured with steel mould meets the test requirements; therefore, the treatment of the 


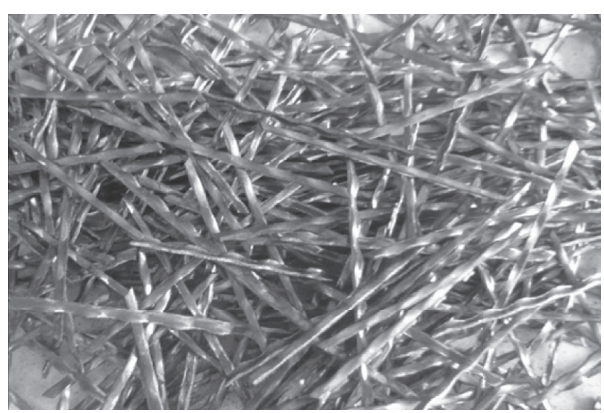

(a)

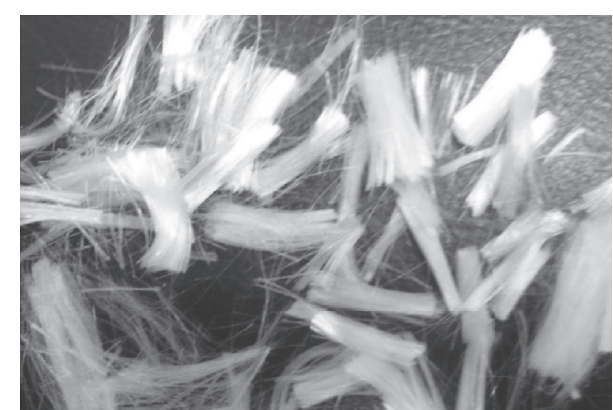

(b)

FIgURE 1: Exterior of fiber: (a) corrugated steel fibers; (b) polypropylene fibers.

TABLE 1: Mix proportion for concrete.

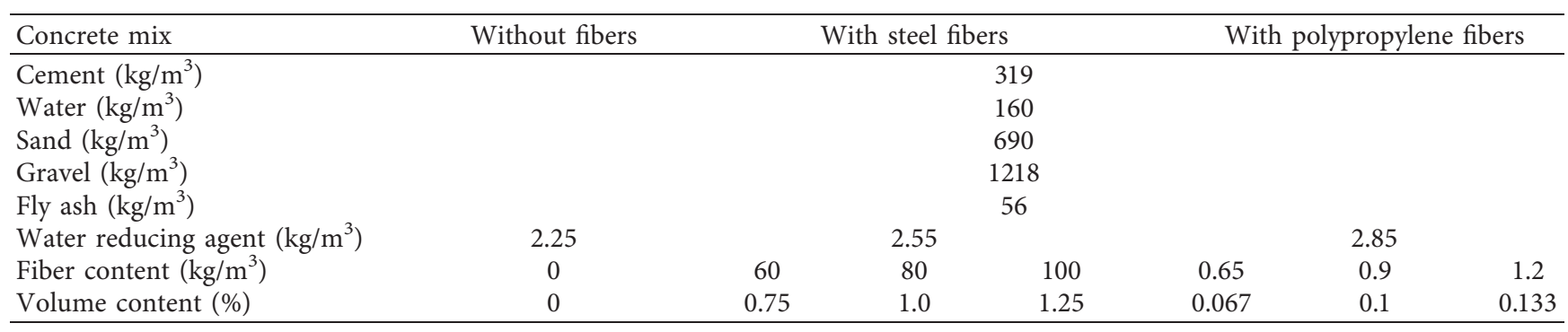

end face and the surface of the specimens could be omitted. Table 3 lists the test conditions of prism specimens.

2.3. Test Equipment. An MTS electrohydraulic servo testing machine with a maximum displacement loading rate of $99 \mathrm{~mm} / \mathrm{s}$ was used to conduct the compression testing for FRC cylinder specimens at different strain rates as shown in Figure 2(a). The static elastic modulus test of FRC prism specimens was carried out on a hydraulic testing machine with a maximum load capacity of $2000 \mathrm{kN}$, as illustrated in Figure 2(b).

As shown in Figure 3, two symmetrical vertical strain gauges and two symmetrical transverse strain gauges were attached to each specimen, respectively. Three displacement transducers with a range of $30 \mathrm{~mm}$ and a reading resolution of $0.01 \mathrm{~mm}$ were used in the compression test at different strain rates. In addition, the pasting method of strain gauges for prism specimens was the same as that for cylindrical specimens, and the strain gauge arrangement of specimens is shown in Figure 3. In order to obtain the complete stressstrain curve of cylinder specimens under different strain rates, two measuring devices, strain gauge and displacement transducer, were used in compression tests at different strain rates. Before the specimen cracks, the strain of the specimen is based on the strain gauge. Subsequently, the strain measured by the displacement meter with accuracy of $0.01 \mathrm{~mm}$ should be taken as the criterion when the strain gauge fails.

\subsection{Loading Scheme}

2.4.1. Loading Scheme of FRC Cylindrical Specimens under Compression at Different Strain Rates. At the beginning of the test, in order to eliminate the gap between specimen and test device, the initial preloading was carried out to stabilize the relationship between load and deformation. Firstly, the load value was uniformly loaded to $F_{1}$ (the first stage load) with a value of $0.5 \mathrm{MPa}$, and $F_{1}$ was maintained for 60 seconds. Subsequently, the load value $F_{2}$ (the second stage load), which is about $1 / 3$ of the axial compressive strength, was loaded uniformly and maintained for 60 seconds. Then, $F_{2}$ was unloaded to $F_{1}$ at the same rate, and $F_{1}$ was maintained for 60 seconds. The preloading was repeated at least twice as described above. The destructive loading test used a constant strain rate to control the loading so as to obtain the ideal stress-strain curve. Furthermore, the MTS machine was controlled by displacement loading control, and the displacement loading speed of the testing machine could be obtained by converting the strain rate into the displacement of the specimen: $0.03045 \mathrm{~mm} / \mathrm{s}, 1.1004 \mathrm{~mm} / \mathrm{s}, 2.52 \mathrm{~mm} / \mathrm{s}$, $9.45 \mathrm{~mm} / \mathrm{s}$, and $21 \mathrm{~mm} / \mathrm{s}$, respectively, correspond to $1.45 \times 10^{-4} / \mathrm{s}, \quad 5.24 \times 10^{-3} / \mathrm{s}, \quad 1.2 \times 10^{-2} / \mathrm{s}, 0.45 \times 10^{-1} / \mathrm{s}$, and $0.1 / \mathrm{s}$.

2.4.2. Loading Scheme for Static Elastic Modulus Test of FRC Prism Specimens. The preloading process was divided into two stages as described earlier, but the deformation value of the corresponding measuring points should be recorded, respectively, within 30 seconds after each stage of loading. Then, we confirm the requirements of alignment and repeat the preloading at least twice as the previous method. Finally, the deformation readings $\varepsilon_{0}$ and $\varepsilon_{\mathrm{a}}$ of each measuring point should be recorded within the next 30 seconds after the reference stress $F_{0}$ and $F_{\mathrm{a}}$ was maintained for 60 seconds, respectively. 
TABLE 2: Test conditions of cylindrical specimens.

\begin{tabular}{lc}
\hline Specimen number & $\dot{\varepsilon}(\mathrm{mm} / \mathrm{s})$ \\
\hline a-n-1 & 0.03045 \\
a-n-2 & 1.1004 \\
a-n-3 & 2.52 \\
a-n-4 & 9.45 \\
a-n-5 & 21 \\
b-p-1 & 0.03045 \\
b-p-2 & 1.1004 \\
b-p-3 & 2.52 \\
b-p-4 & 9.45 \\
b-p-5 & 21 \\
c-p-1 & 0.03045 \\
c-p-2 & 1.1004 \\
c-p-3 & 2.52 \\
c-p-4 & 9.45 \\
c-p-5 & 21 \\
d-p-1 & 0.03045 \\
d-p-2 & 1.1004 \\
d-p-3 & 2.52 \\
d-p-4 & 9.45 \\
d-p-5 & 21 \\
e-s-1 & 0.03045 \\
e-s-2 & 1.1004 \\
e-s-3 & 2.52 \\
e-s-4 & 9.45 \\
e-s-5 & 21 \\
f-s-1 & 0.03045 \\
f-s-2 & 1.1004 \\
f-s-3 & 2.52 \\
f-s-4 & 9.45 \\
f-s-5 & 21 \\
g-s-1 & 0.03045 \\
g-s-2 & 1.1004 \\
g-s-3 & 2.52 \\
g-s-4 & 9.45 \\
g-s-5 & 21 \\
\hline Note: & \\
\hline
\end{tabular}

Note: $a, b, c, d, e, f$, and g represent $0,0.6,0.9,1.2,60,80$, and $100 \mathrm{~kg} / \mathrm{m}^{3}$ of fiber content, respectively. $\mathrm{n}, \mathrm{p}$, and $\mathrm{s}$ represent plain concrete, PFRC, and SFRC, respectively. $\dot{\varepsilon}$ represents loading rate. The displacement loading rates of $0.03045 \mathrm{~mm} / \mathrm{s}, 1.1004 \mathrm{~mm} / \mathrm{s}, 2.52 \mathrm{~mm} / \mathrm{s}, 9.45 \mathrm{~mm} / \mathrm{s}$, and $21 \mathrm{~mm} / \mathrm{s}$, respectively, correspond to $1.45 \times 10^{-4} / \mathrm{s}, 5.24 \times 10^{-3} / \mathrm{s}, 1.2 \times 10^{-2} / \mathrm{s}$, $0.45 \times 10^{-1} / \mathrm{s}$, and $0.1 / \mathrm{s}$

TABle 3: Test conditions of prism specimens.

\begin{tabular}{lcc}
\hline Specimen number & Fiber species & $V_{\mathrm{f}}\left(\mathrm{kg} / \mathrm{m}^{3}\right)$ \\
\hline a-p-0 & None & 0 \\
b-p-0 & Polypropylene fiber & 0.6 \\
c-p-0 & Polypropylene fiber & 0.9 \\
d-p-0 & Polypropylene fiber & 1.2 \\
e-s-0 & Steel fiber & 60 \\
f-s-0 & Steel fiber & 80 \\
g-s-0 & Steel fiber & 100 \\
\hline
\end{tabular}

Note: $\mathrm{a}, \mathrm{b}, \mathrm{c}, \mathrm{d}, \mathrm{e}, \mathrm{f}$, and g represent $0,0.6,0.9,1.2,60,80$, and $100 \mathrm{~kg} / \mathrm{m}^{3}$ of fiber content, respectively. $p$ and $s$ represent PFRC and SFRC, respectively. 0 represents the prism specimen. $V_{\mathrm{f}}$ represents fiber content.

\section{Results and Analysis}

3.1. Compression Test Results and Analysis at Different Strain Rates. In this paper, the mechanical properties are analyzed by the whole compression test of SFRC and PFRC with different fiber contents at different strain rates. Figure 4 shows typical failure of each group of specimens in this test. It can be seen that the failure degree of FRC is lower than that of plain concrete, and SFRC shows obvious shear failure. Herein, this section provides an in-depth analysis of the effect of fiber content and strain rate on dominant characteristic parameters of SFRC and PFRC such as dynamic increase factor (DIF), peak stress, peak strain, and toughness. Moreover, the average value obtained from the three identical specimens for each condition was calculated as the typical value. Subsequently, the detailed results for each specimen with respect to the peak stress, peak strain, and toughness are summarized in Table 4 . Figure 5 illustrates the dynamic compressive stress-strain curves of SFRC and PFRC subjected to different strain rate loading, of which stress value is the average of three repeated tests.

3.2. Effect of Fiber Content on Mechanical Properties of Concrete. In order to better analyze the effect of fibers on the mechanical properties of concrete, this paper introduces definitions of dynamic compressive strength ratio (DCSR), peak strain ratio (PSR), toughness ratio (TR), and dynamic increase factor (DIF). These parameters are calculated by the following formula:

$$
\operatorname{DCSR}=\frac{\mathrm{PS}_{\text {stress }}}{\mathrm{PS}_{\text {stress }}^{\prime}}
$$

where $\mathrm{PS}_{\text {stress }}$ is the peak stress of FRC and PS $S_{\text {stress }}^{\prime}$ is the peak stress of plain concrete under the same conditions.

$$
\mathrm{PSR}=\frac{\mathrm{PS}_{\text {strain }}}{\mathrm{PS}_{\text {strain }}^{\prime}},
$$

where $\mathrm{PS}_{\text {strain }}$ is the peak strain of FRC and $\mathrm{PS}_{\text {strain }}^{\prime}$ is the peak strain of plain concrete under the same conditions.

$$
\mathrm{TR}=\frac{T}{T^{\prime}}
$$

where $T$ is the toughness of FRC and $T^{\prime}$ is the toughness of plain concrete under the same conditions.

$$
\mathrm{DIF}=\frac{f_{\mathrm{c}}^{\mathrm{d}}}{f_{\mathrm{c}}^{\mathrm{s}}},
$$

where $f_{\mathrm{c}}^{\mathrm{d}}$ is the dynamic compressive strength of FRC and $f_{\mathrm{c}}^{\mathrm{s}}$ is the compressive strength at $\dot{\varepsilon}=1.45 \times 10^{-4} / \mathrm{s}$.

It is evident that the addition of polypropylene fibers improves the dynamic compressive strength of concrete, as shown in Figure 6(a). More specifically, the overall tendency of the relationship between polypropylene fiber content and dynamic compressive strength is increasing, but the increment of the peak stress is less and less. Additionally, dynamic compressive strength, peak strain, and toughness all increase with the volume fraction of polypropylene fibers. It is apparent from Figures 6(b)-6(d) that the DCSR, PSR, and TR of PFRC are obviously improved as the polypropylene fiber content increases for all strain rates. For example, PFRC with $0.067 \%$ fiber content at $\dot{\varepsilon}=1.45 \times 10^{-4} / \mathrm{s}$ has an increased 


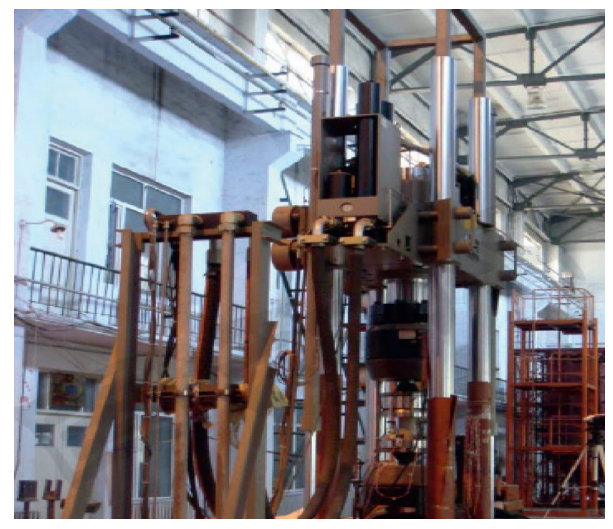

(a)

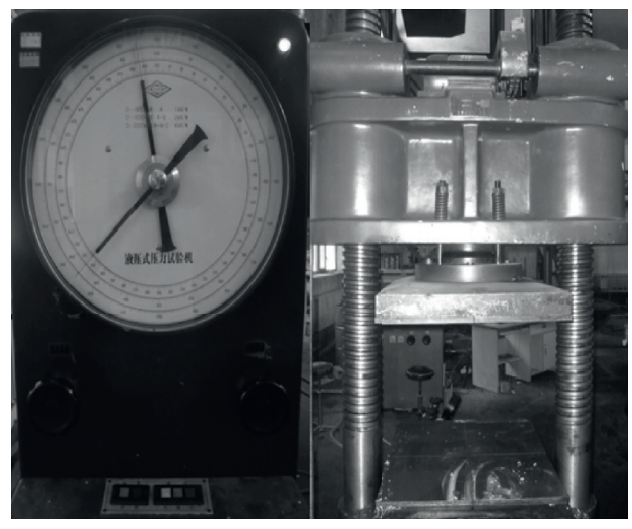

(b)

FIgURe 2: Test equipment: (a) MTS electrohydraulic servo testing machine; (b) hydraulic testing machine.

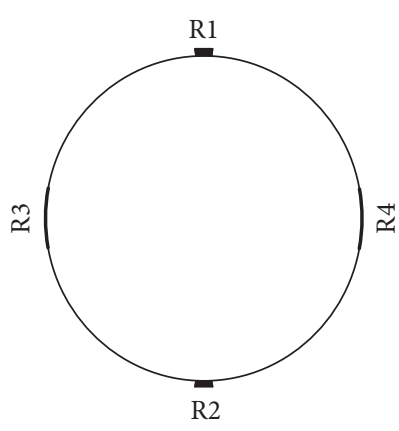

(a)

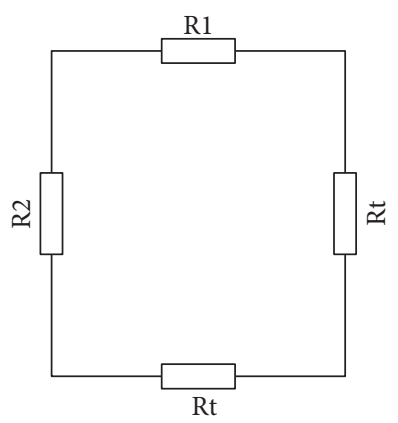

(b)

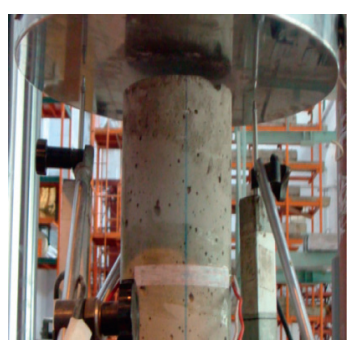

(c)

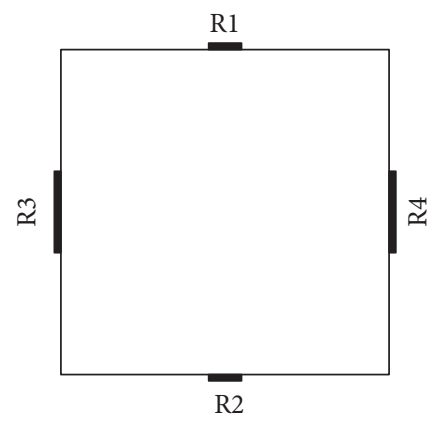

(d)

FIGURE 3: Measuring arrangement and connection mode of vertical strain gauge: (a) cylinder specimen profile; (b) connection of vertical strain gauges; (c) position of displacement meter; (d) prism specimen profile. Note: R1 and R2 are vertical strain gauges, R3 and R4 are transverse strain gauges, and Rt is temperature compensation strain gauge.

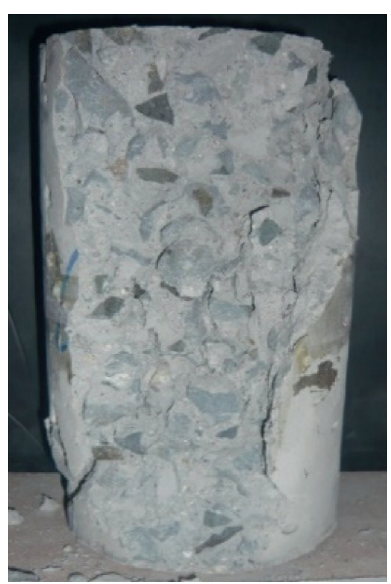

(a)

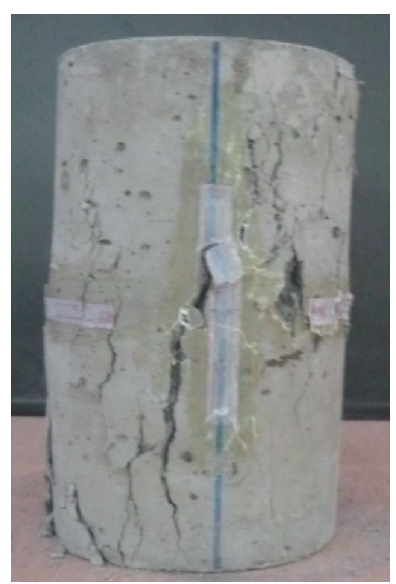

(b)

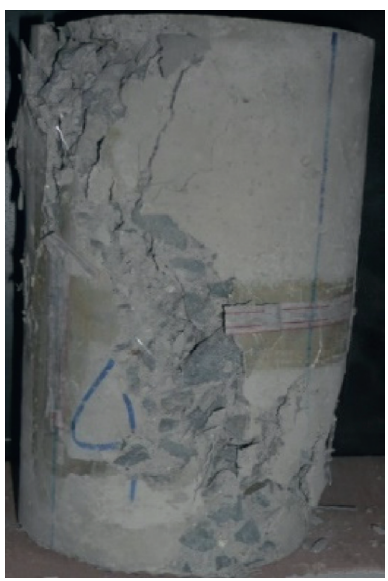

(c)

Figure 4: Typical failure diagram: (a) specimen a-n-1; (b) specimen b-p-1; (c) specimen e-s-1.

peak stress, peak strain, and toughness up to $27.8 \%, 8 \%$, and $35.6 \%$, respectively.

Figure 7 illustrates the dynamic compressive stressstrain curves of SFRC at $\dot{\varepsilon}=1.45 \times 10^{-4}$ and the relationship between steel fiber content and DCSR, PSR, and TR of SFRC.
It can be seen that the overall tendency of the relationship between steel fiber content and dynamic compressive strength is increasing, and the peak stress increases more and more, as shown in Figure 7(a). In addition, dynamic compressive strength, peak strain, and toughness all increase 
TABle 4: Main experimental results of cylindrical specimens.

\begin{tabular}{|c|c|c|c|}
\hline Specimen number & Peak stress $(\mathrm{MPa})$ & Peak strain & Toughness \\
\hline a-n-1 & 16.9 & 0.00336 & 0.1269 \\
\hline$a-n-2$ & 18.7 & 0.00357 & 0.1707 \\
\hline$a-n-3$ & 19.4 & 0.00381 & 0.1735 \\
\hline$a-n-4$ & 20.1 & 0.00392 & 0.1858 \\
\hline$a-n-5$ & 21.6 & 0.0041 & 0.1280 \\
\hline b-p-1 & 21.6 & 0.00363 & 0.1721 \\
\hline b-p-2 & 24.2 & 0.00387 & 0.2094 \\
\hline$b-p-3$ & 25.4 & 0.00412 & 0.2478 \\
\hline b-p-4 & 26.5 & 0.00431 & 0.2318 \\
\hline$b-p-5$ & 28.9 & 0.00453 & 0.3665 \\
\hline$c-p-1$ & 23.0 & 0.00414 & 0.2119 \\
\hline$c-p-2$ & 25.4 & 0.00428 & 0.2449 \\
\hline$c-p-3$ & 26.3 & 0.00449 & 0.2433 \\
\hline$c-p-4$ & 9.45 & 0.00477 & 0.2872 \\
\hline$c-p-5$ & 31.3 & 0.00492 & 0.3681 \\
\hline d-p-1 & 2.8 & 0.00476 & 0.2706 \\
\hline d-p-2 & 26.3 & 0.00494 & 0.2974 \\
\hline d-p-3 & 27.4 & 0.00512 & 0.3425 \\
\hline d-p-4 & 30.0 & 0.00551 & 0.3839 \\
\hline d-p-5 & 31.9 & 0.00598 & 0.4691 \\
\hline e-s-1 & 24.4 & 0.0046 & 0.1519 \\
\hline e-s-2 & 27.3 & 0.0052 & 0.3369 \\
\hline e-s-3 & 29.1 & 0.00536 & 0.3651 \\
\hline e-s-4 & 32.6 & 0.00565 & 0.3286 \\
\hline e-s-5 & 34 & 0.00622 & 0.4351 \\
\hline f-s-1 & 25.3 & 0.00507 & 0.4690 \\
\hline f-s-2 & 28.5 & 0.00615 & 0.3123 \\
\hline$f-s-3$ & 31.1 & 0.00645 & 0.5567 \\
\hline f-s-4 & 33.6 & 0.00712 & 0.6272 \\
\hline$f-s-5$ & 37 & 0.00761 & 0.5045 \\
\hline g-s-1 & 28.2 & 0.00567 & 0.3370 \\
\hline g-s-2 & 33.0 & 0.00644 & 0.5492 \\
\hline g-s-3 & 34.5 & 0.00745 & 0.6503 \\
\hline g-s-4 & 36.3 & 0.00791 & 0.8063 \\
\hline g-s-5 & 40.9 & 0.00815 & 0.9213 \\
\hline
\end{tabular}

Note: Peak strain, peak stress and toughness are the average values of three experiments. Toughness is the area of the stress-strain curve before peak stress.

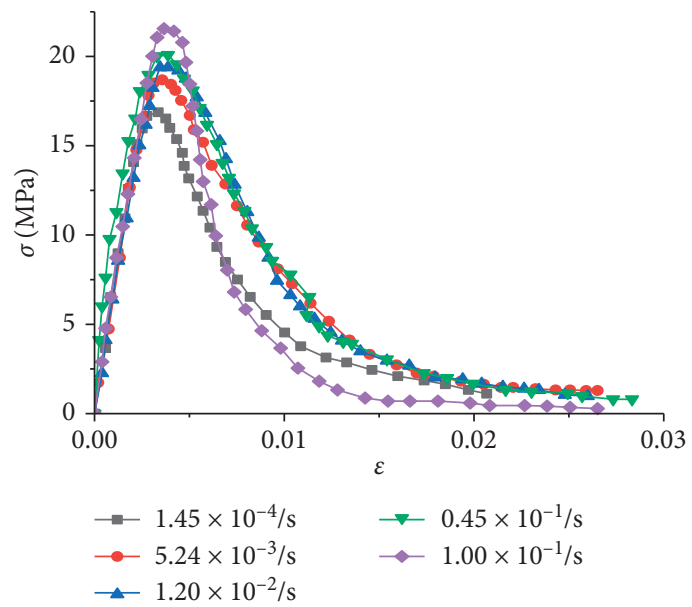

(a)

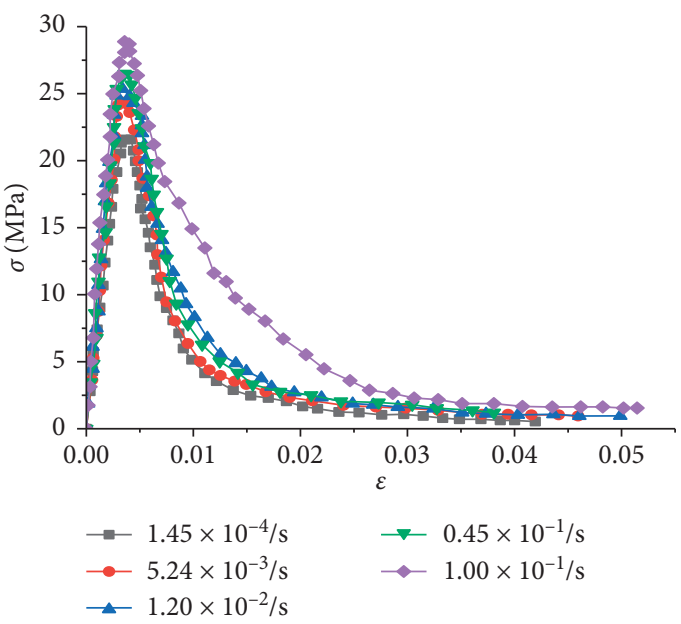

(b)

Figure 5: Continued. 

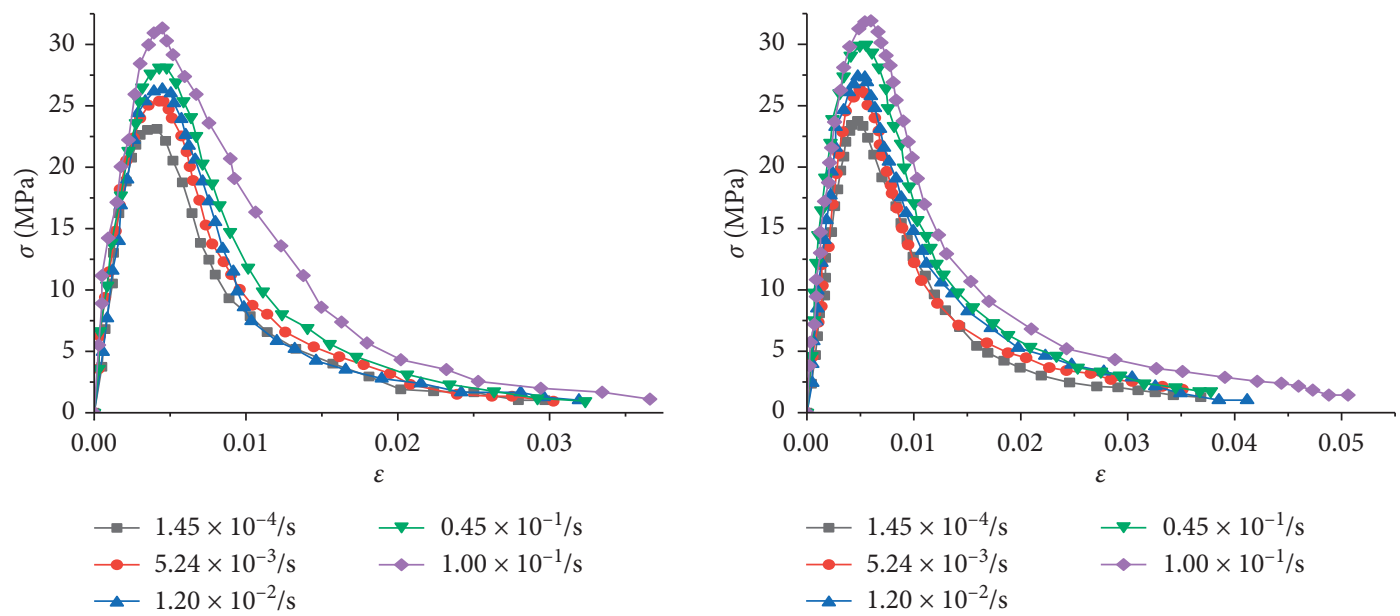

(c)

(d)

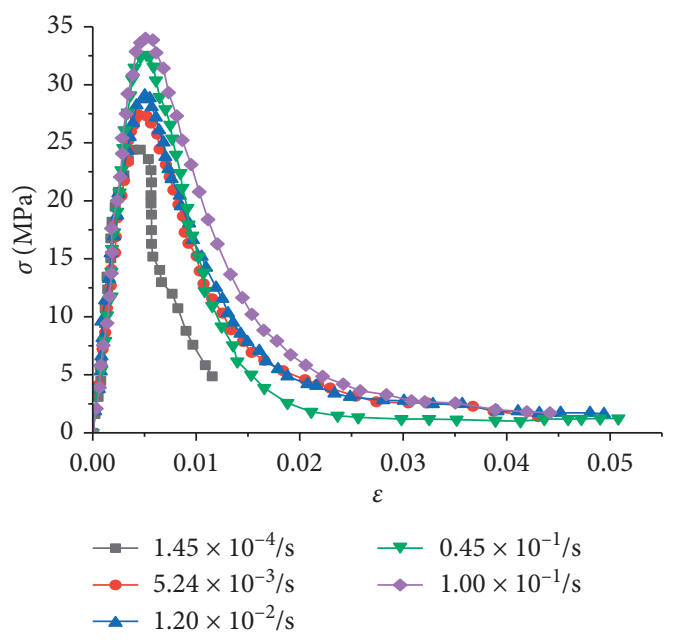

(e)

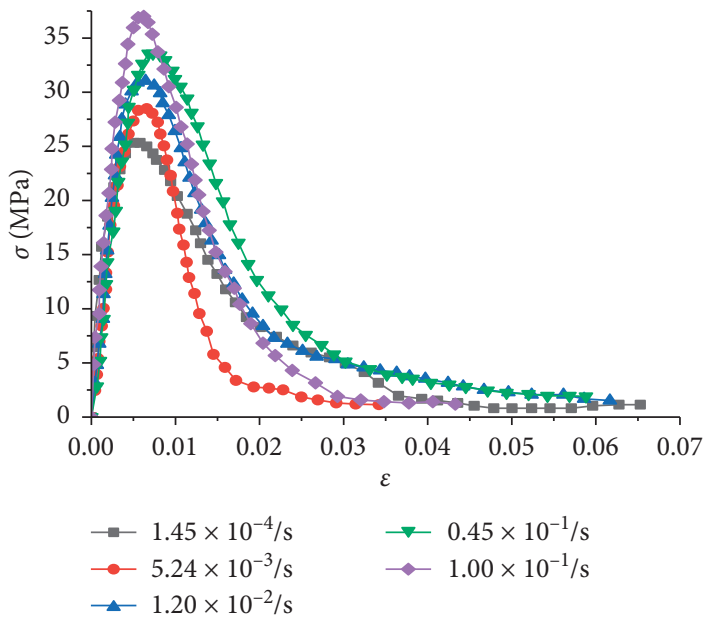

(f)

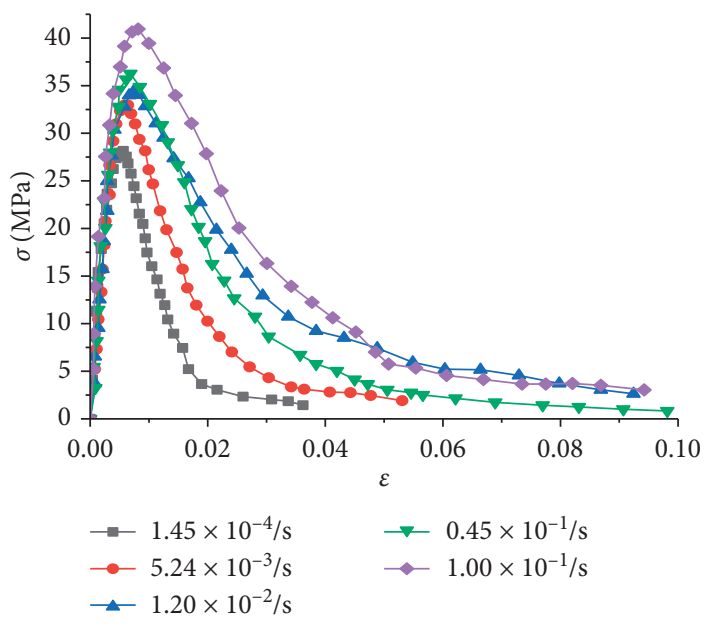

(g)

FIGURE 5: The dynamic compressive stress-strain curves of concrete specimens under different strain rates: (a) plain concrete; (b) PFRC with $V_{\mathrm{f}}=0.067 \%$; (c) PFRC with $V_{\mathrm{f}}=0.1 \%$; (d) PFRC with $V_{\mathrm{f}}=0.133 \%$; (e) SFRC with $V_{\mathrm{f}}=0.75 \%$; (f) SFRC with $V_{\mathrm{f}}=1.0 \%$; (g) SFRC with $V_{\mathrm{f}}=1.25 \%$. 


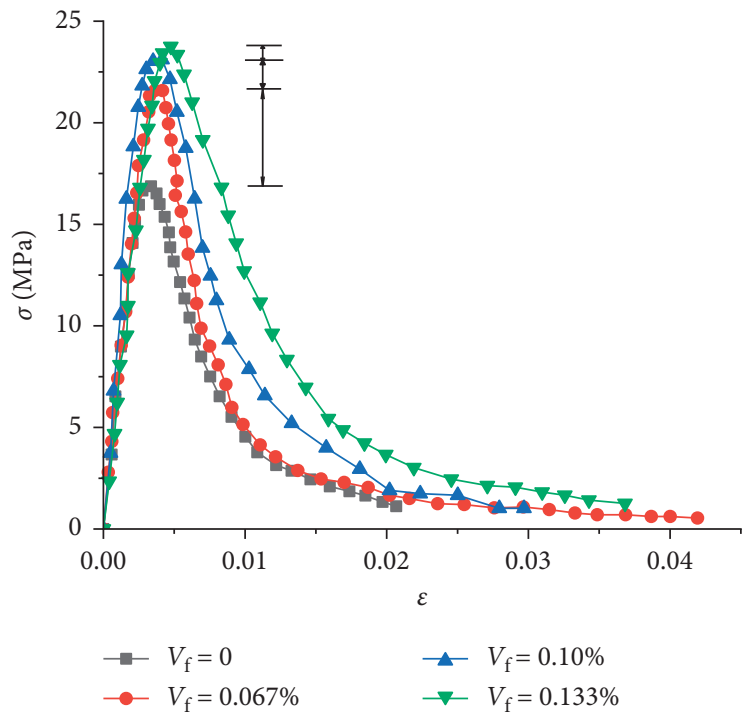

(a)

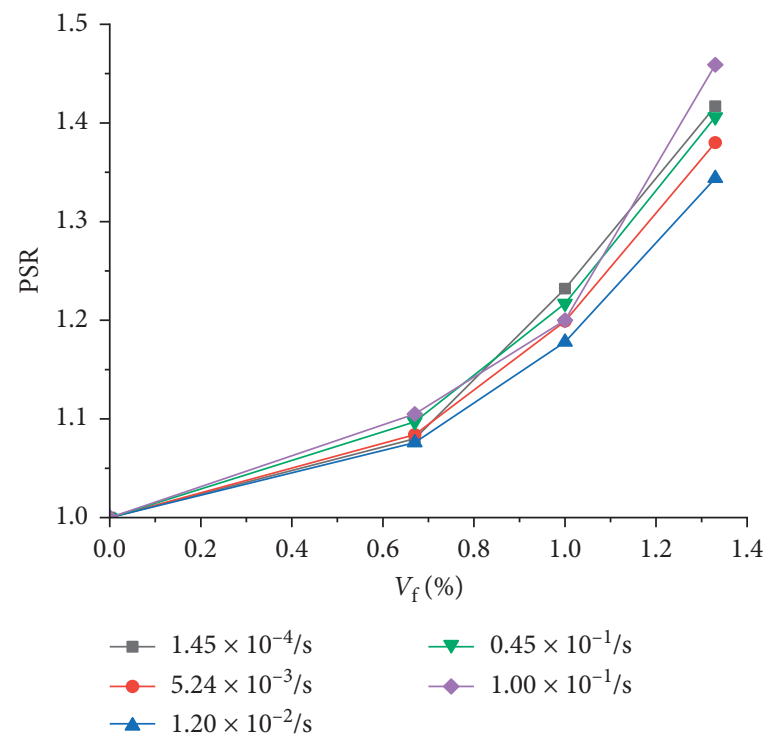

(c)

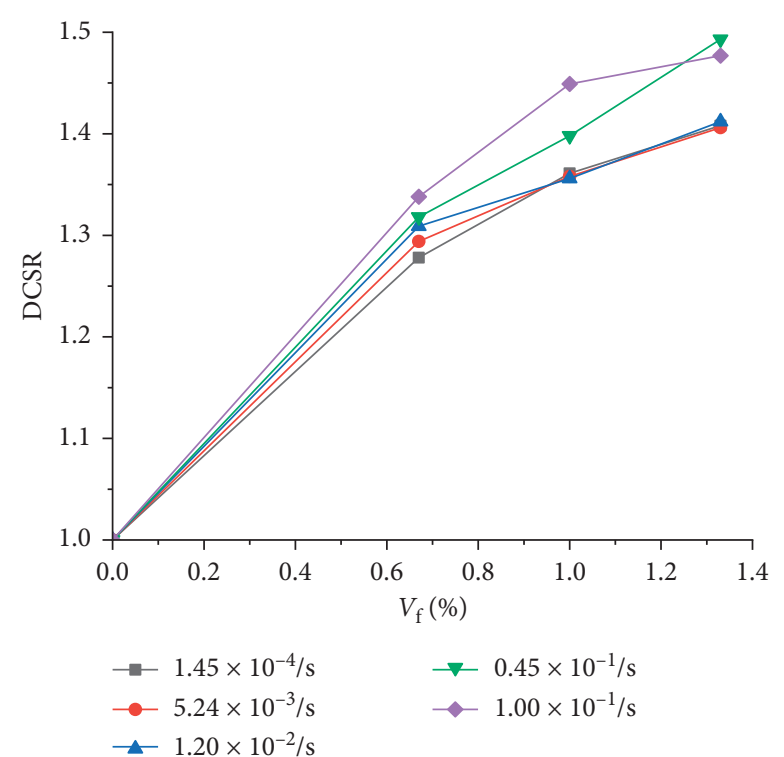

(b)

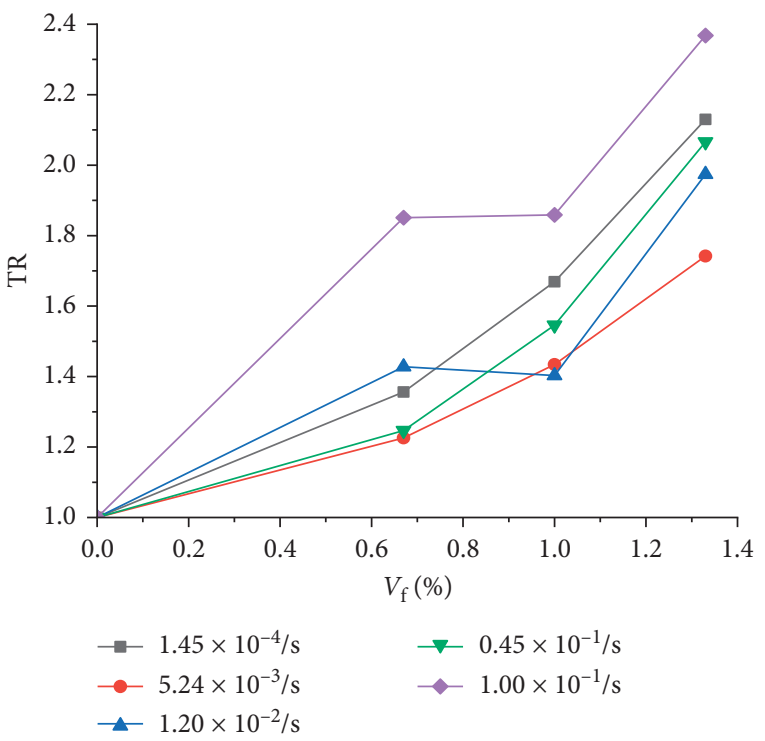

(d)

Figure 6: (a) Dynamic compressive stress-strain curves of PFRC at $\dot{\varepsilon}=1.45 \times 10^{-4} / \mathrm{s}$. (b) Relationship between polypropylene fiber content $\left(V_{\mathrm{f}}\right)$ and DCSR of PFRC. (c) Relationship between polypropylene fiber content $\left(V_{\mathrm{f}}\right)$ and PSR of PFRC. (d) Relationship between polypropylene fiber content $\left(V_{\mathrm{f}}\right)$ and TR of PFRC.

with the volume fraction of steel fibers. It is evident from Figures 7(b)-7(d) that the DCSR, PSR, and TR of SFRC are, respectively, higher than those of plain concrete. It can be seen that from Figures $7(\mathrm{~b})-7(\mathrm{~d})$ that the increase in DCSR, PSR, and TR of SFRC as the steel fiber content increases for all strain rates. For example, the peak stress, peak strain, and toughness of SFRC with $0.75 \%$ fiber content at $\dot{\varepsilon}=1.45 \times 10^{-4} / \mathrm{s}$ increased by $44.4 \%, 36.9 \%$, and $19.7 \%$, respectively.

3.3. Analysis of Strain Rate Effect of PFRC and SFRC. Here, DIF is defined as the value of the dynamic compressive strength divided by the static strength of FRC specimens with the same fiber content, as shown in equation (4). However, there is no standard static compression test in this paper, and the compressive strength at $\dot{\varepsilon}=1.45 \times 10^{-4} / \mathrm{s}$ is used as the reference static strength. It reflects the increase in the compressive strength of concrete subjected to impact loading and is broadly used in concrete structure design. Tedesco et al. [24] considered the relationship between DIF and the logarithm of strain rate $(\lg \dot{\varepsilon})$ to be approximately linear. Therefore, the linear regression analysis was performed for the relationship between DIF and $\lg \dot{\varepsilon}$ in each condition. In addition, the results of the linear fitting are plotted in Figure 8, and the corresponding fitted functions are tabulated in Table 5. The fitting results show that the DIF 


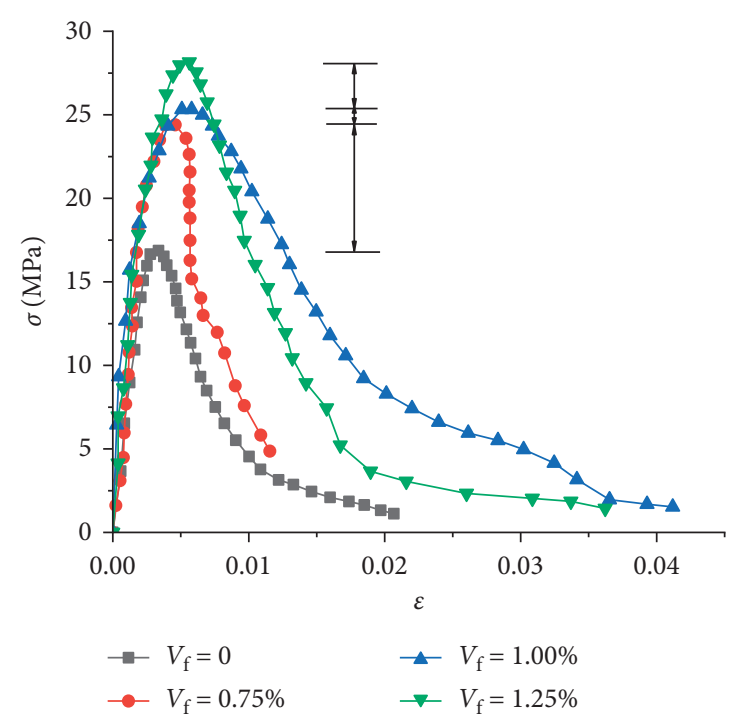

(a)

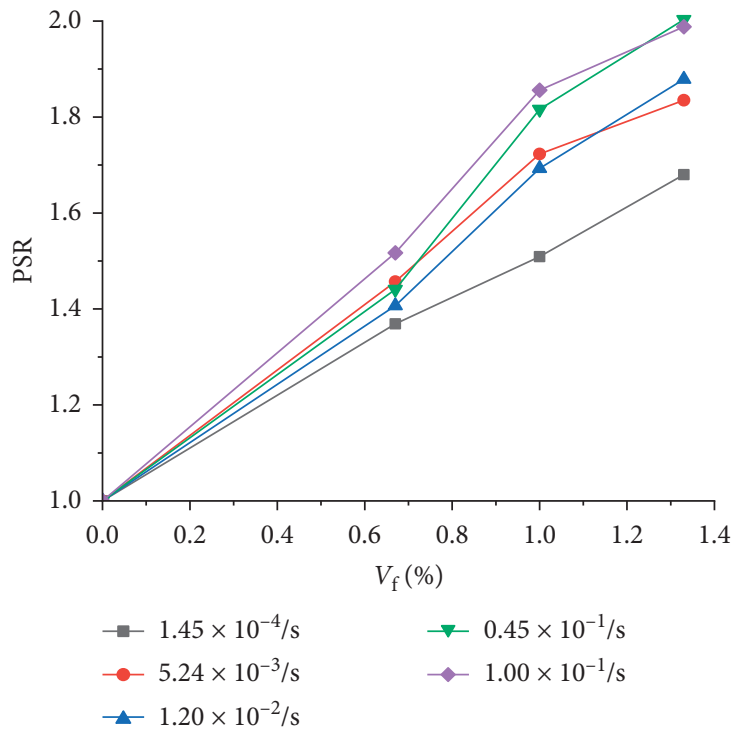

(c)

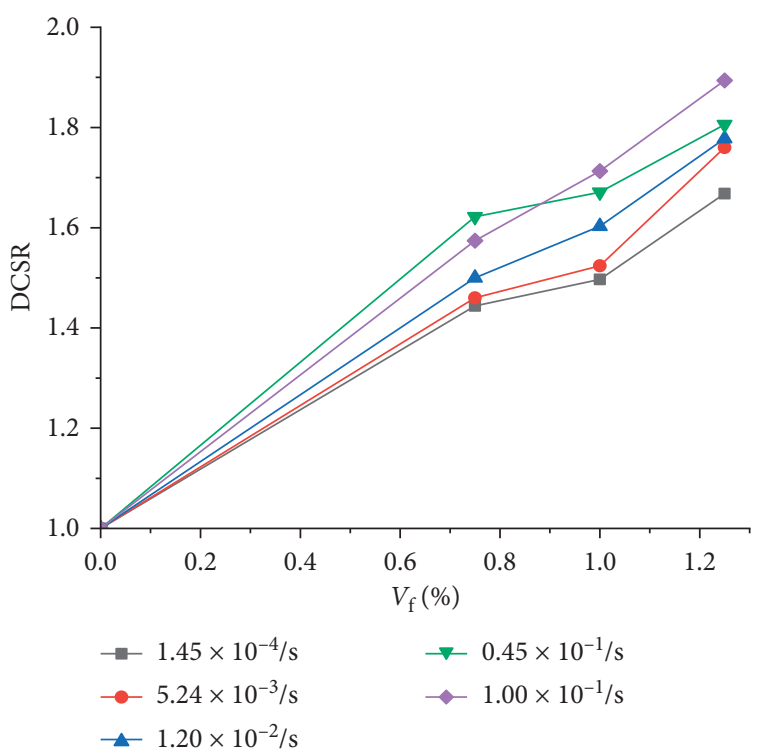

(b)

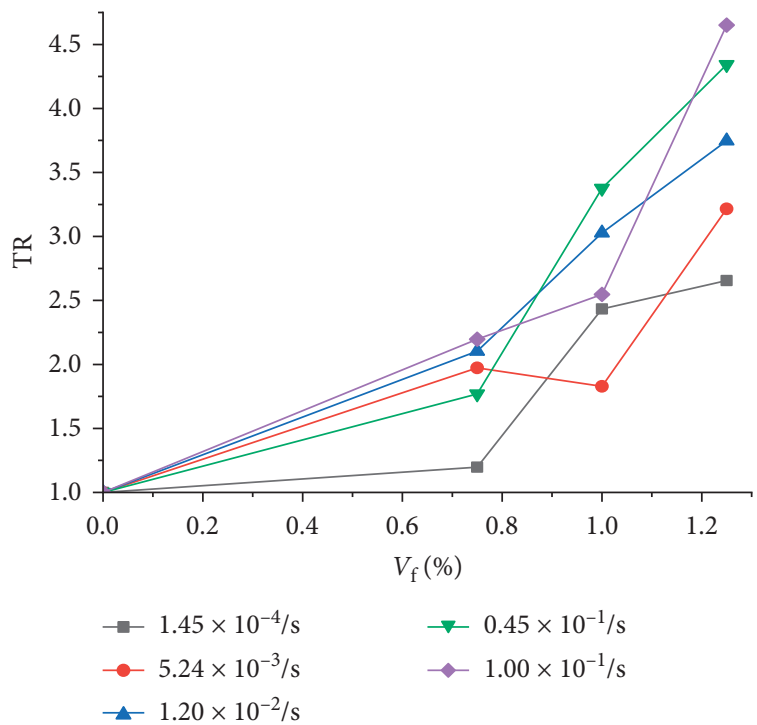

(d)

FiguRE 7: (a) Dynamic compressive stress-strain curves of SFRC at $\dot{\varepsilon}=1.45 \times 10^{-4} / \mathrm{s}$. (b) Relationship between steel fiber content $\left(V_{\mathrm{f}}\right.$ ) and DCSR of SFRC. (c) Relationship between steel fiber content $\left(V_{\mathrm{f}}\right)$ and PSR of SFRC. (d) Relationship between steel fiber content $\left(V_{\mathrm{f}}\right)$ and TR of SFRC.

of concrete increases with the increasing strain rate, indicating that the failure of concrete specimens has obvious strain rate enhancement effect.

The peak strain-strain rate curves of FRC specimens at different strain rates are plotted with the data in Table 5, as shown in Figure 9. It can be found that the dynamic toughening effects on FRC specimens, and the peak strain increases as the strain rate increases. According to the curve shape of Figure 9, the appropriate function $\varepsilon_{\mathrm{p}}=A+B \lg \dot{\varepsilon}+$ $C(\lg \dot{\varepsilon})^{2}$ is selected to fit the data. The results of the fitting are plotted in Figure 9, and the corresponding fitted functions are tabulated in Table 5.
This paper considers that peak toughness $(R)$ is the area of the stress-strain curve before peak stress, and the dynamic toughness of concrete with different fibers and different fibers content varies with the strain rate as shown in Figure 10. Then, according to the change rule, the appropriate function $R_{\mathrm{p}}=A+B \lg \dot{\varepsilon}+C(\lg \dot{\varepsilon})^{2}$ is selected to fit the data. The results of the fitting are plotted in Figure 10, and the corresponding fitted functions are tabulated in Table 5.

From the stress-strain curves of each FRC specimen, it could be found that the elastic modulus of FRC does not change obviously with the increasing strain rate. The failure modes of the specimens at different strain rates are quite 


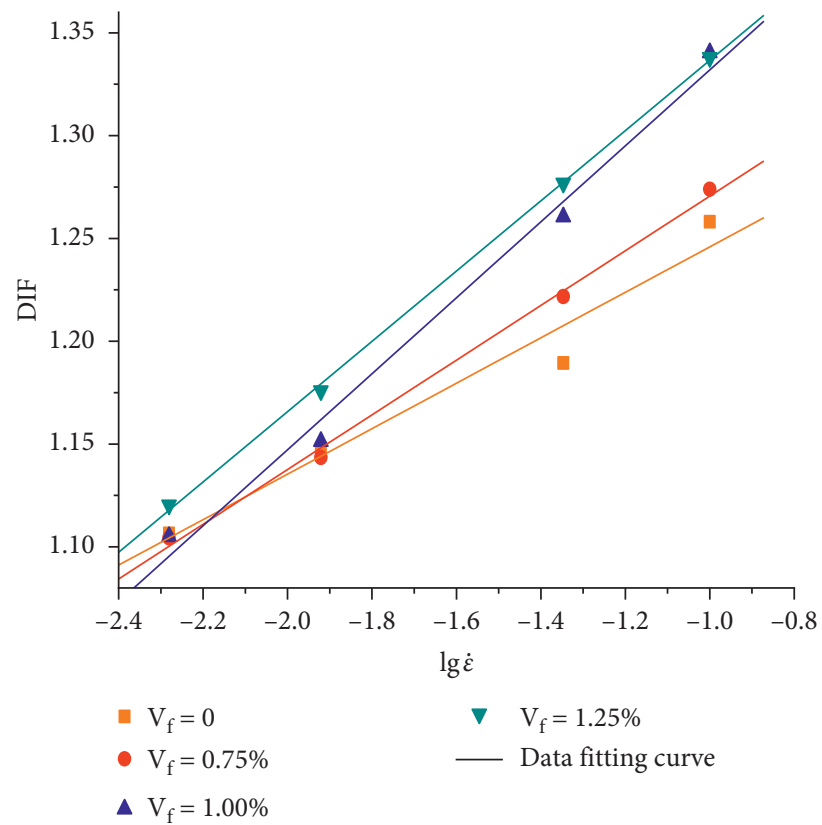

(a)

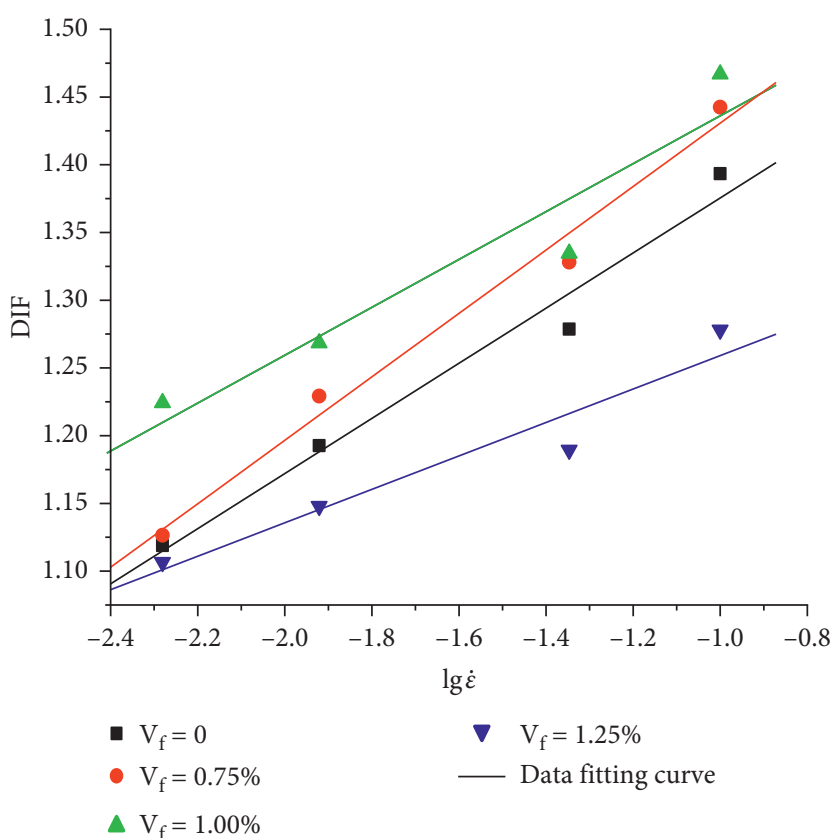

(b)

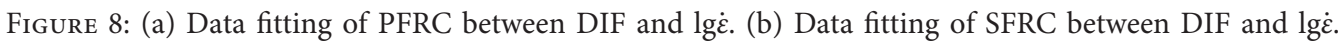

TABLE 5: Fitted DIF functions.

\begin{tabular}{|c|c|c|c|c|c|c|c|c|}
\hline \multirow{2}{*}{$V_{\mathrm{f}}$} & \multicolumn{2}{|c|}{$\mathrm{DIF}=A+B \lg \dot{\varepsilon}$} & \multicolumn{3}{|c|}{$\varepsilon_{\mathrm{p}}=A+B \lg \dot{\varepsilon}+C(\lg \dot{\varepsilon})^{2}$} & \multicolumn{3}{|c|}{$R_{\mathrm{p}}=A+B \lg \dot{\varepsilon}+C(\lg \dot{\varepsilon})^{2}$} \\
\hline & $\mathrm{A}$ & B & A & $\mathrm{B}$ & $\mathrm{C}$ & $\mathrm{A}$ & $\mathrm{B}$ & $\mathrm{C}$ \\
\hline $0.000 \%$ (plain concrete) & 1.3321 & 0.0904 & 0.0046 & 0.006 & 0.00007 & 0.215 & 0.0179 & -0.0013 \\
\hline $0.067 \%$ (PFRC) & 1.3990 & 0.1100 & 0.0053 & 0.0008 & 0.0001 & 0.503 & 0.2010 & 0.0300 \\
\hline $0.100 \%$ (PFRC) & 1.3450 & 0.0940 & 0.0057 & 0.0009 & 0.0001 & 0.522 & 0.2000 & 0.0310 \\
\hline $0.133 \%$ (PFRC) & 1.4100 & 0.9500 & 0.0073 & 0.0016 & 0.0002 & 0.669 & 0.2480 & 0.0370 \\
\hline $0.750 \%$ (SFRC) & 1.4670 & 0.1300 & 0.0072 & 0.0013 & 0.0002 & 0.755 & 0.2740 & 0.0374 \\
\hline $1.000 \%$ (SFRC) & 1.5490 & 0.1540 & 0.0091 & 0.0017 & 0.0002 & 1.209 & 0.5860 & 0.0861 \\
\hline $1.250 \%$ (SFRC) & 1.5010 & 0.1350 & 0.0099 & 0.0018 & 0.0002 & 1.325 & 0.4530 & 0.0510 \\
\hline
\end{tabular}

different, and the failure degree of specimens increases with the increasing strain rates, which could be seen from these pictures of the specimens after failure.

3.4. Static Elastic Modulus Test Results and Analysis. The elastic modulus of each FRC specimen could be calculated using the following equation [25]:

$$
E_{0}=\frac{\sigma}{\varepsilon}=\frac{F_{\mathrm{a}}-F_{0}}{A\left(\varepsilon_{\mathrm{a}}-\varepsilon_{0}\right)},
$$

where $E_{0}$ represents the elastic modulus of concrete; $F_{\mathrm{a}}$ represents the load when the stress is $1 / 3$ of the axial compressive strength; $F_{0}$ represents the initial load when the stress is $0.5 \mathrm{MPa}$; A represents the compressive area of the specimen; $\varepsilon_{\text {a }}$ represents the average strain on both sides of specimen under load $F_{\mathrm{a}} ; \varepsilon_{0}$ represents the average strain on both sides of specimen under load $F_{0}$.

The compressive area of the specimens is $10 \times 10^{3} \mathrm{~mm}^{2}$, and the first stage load $\left(F_{0}\right)$ is $5 \times 10^{3} \mathrm{~N}$. Table 6 summarizes all the test data needed to calculate the elastic modulus of each concrete specimen, of which each one is an average obtained from three repeated tests.

For example, according to the experimental data, the elastic modulus of specimen a-p-1 can be calculated based on the experimental data in Table 6 using equation (5) as follows:

$$
\begin{aligned}
E_{0} & =\frac{F_{\mathrm{a}}-F_{0}}{A\left(\varepsilon_{\mathrm{a}}-\varepsilon_{0}\right)}=\frac{70000-5000}{10000 \times\left(219 \times 10^{-6}-14 \times 10^{-6}\right)} \\
& =3.17 \times 10^{4} \mathrm{~N} / \mathrm{mm}^{2} .
\end{aligned}
$$

The results of elastic modulus calculation for other groups are also summarized in Table 6 . It could be seen that both polypropylene fiber and steel fiber could improve the elastic modulus of concrete to some extent, but not obvious. Furthermore, the increase of concrete's elastic modulus by steel fibers is larger than that by polypropylene ones. 


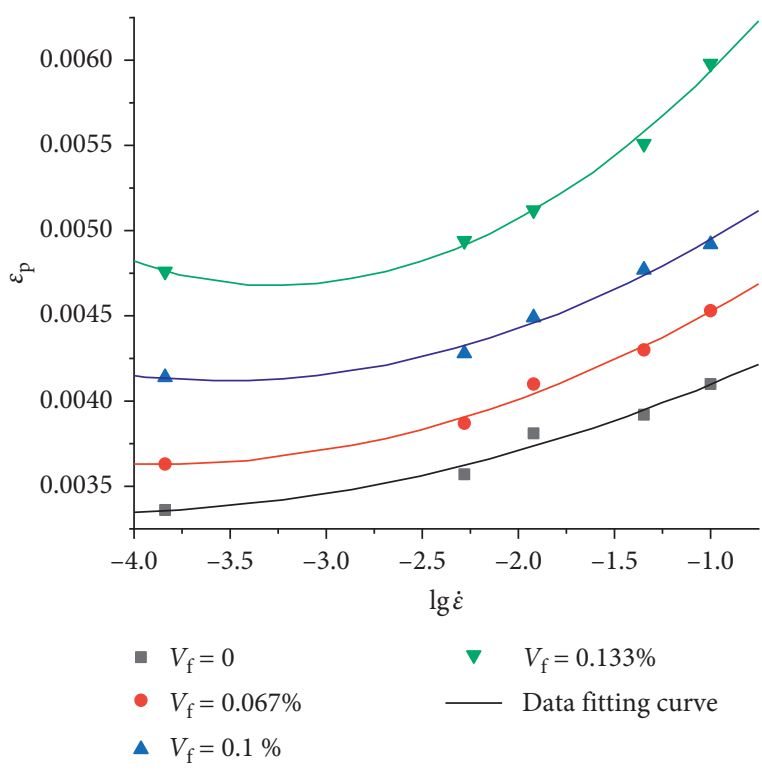

(a)

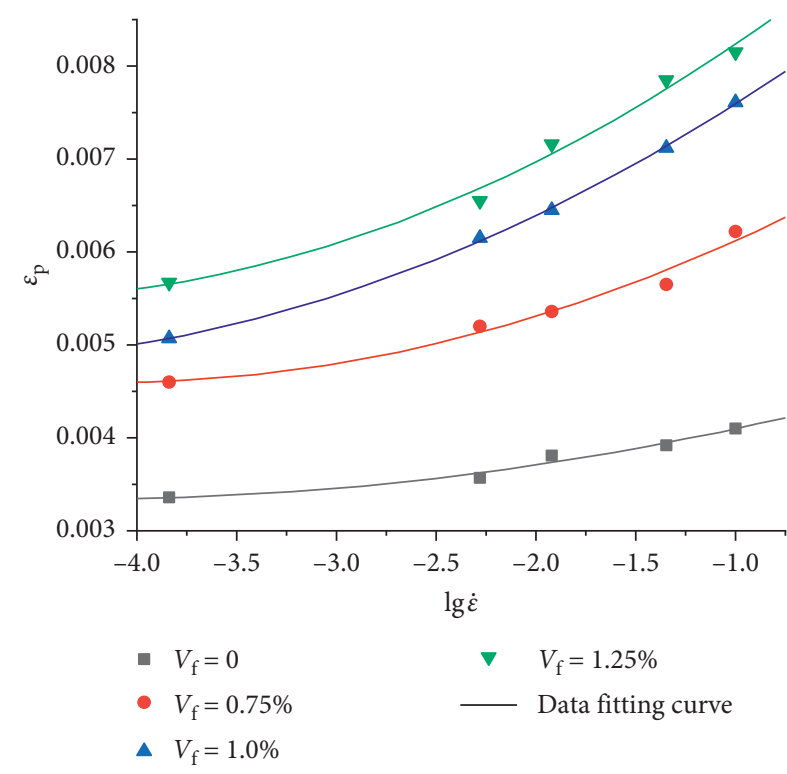

(b)

Figure 9: (a) The variation and data fitting of $\varepsilon_{\mathrm{p}}$ and lg $\dot{\varepsilon}$ of PFRC. (b) The variation and data fitting of $\varepsilon_{\mathrm{p}}$ and lge of SFRC.

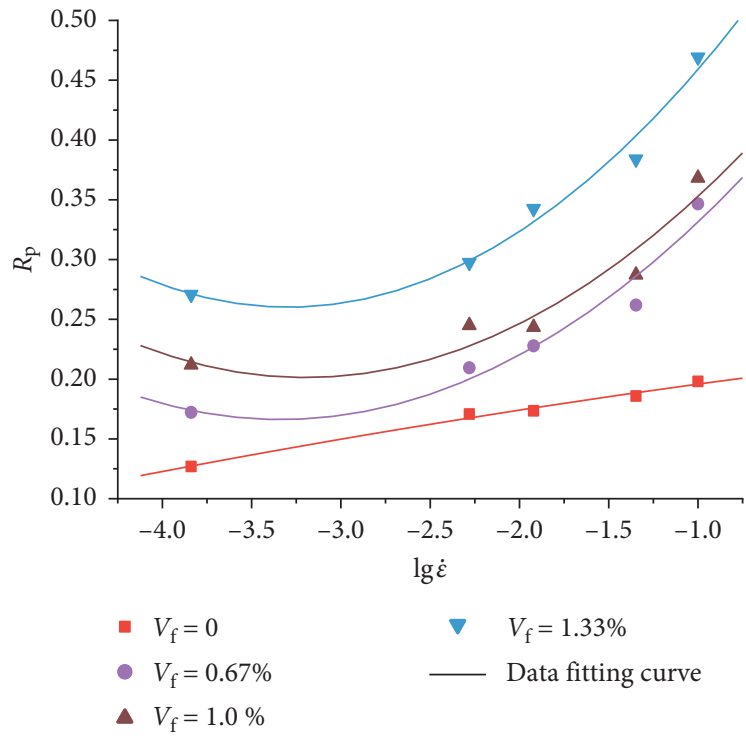

(a)

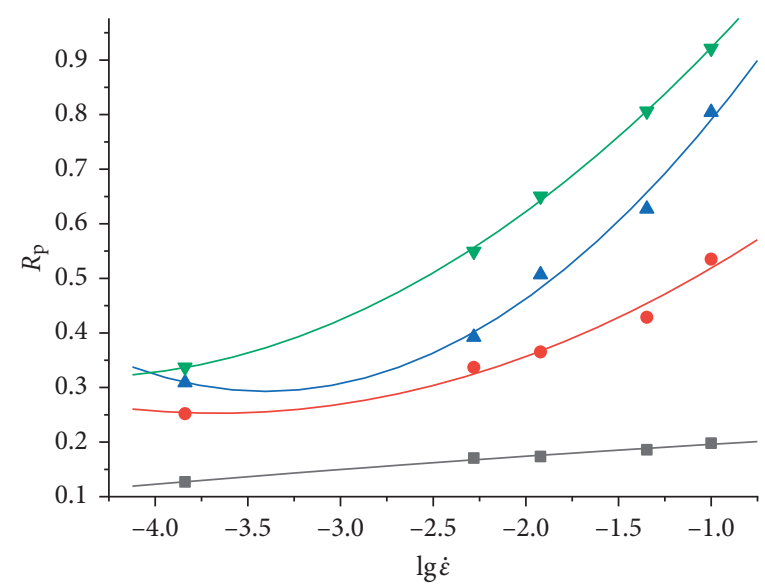

- $V_{\mathrm{f}}=0$

- $V_{\mathrm{f}}=0.75 \%$

$\nabla \quad V_{\mathrm{f}}=1.25 \%$

- $V_{\mathrm{f}}=1.0 \%$

(b)

Figure 10: (a) Data fitting of $R_{\mathrm{p}}$ and lge $\dot{\varepsilon}$ of PFRC. (b) Data fitting of $R_{\mathrm{p}}$ and lge of SFRC.

TABLe 6: Test results of static elastic modulus test.

\begin{tabular}{lcccccc}
\hline Specimen number & Fiber species & $F_{\mathrm{a}}\left(10^{3} \mathrm{~N}\right)$ & $\varepsilon_{0}$ & $\varepsilon_{\mathrm{a}}$ & $V_{\mathrm{f}}\left(\mathrm{kg} / \mathrm{m}^{3}\right)$ & Elastic modulus $\left(10^{4} \mathrm{~N} / \mathrm{mm}^{2}\right)$ \\
\hline a-p-0 & None & 70 & 14.0 & 219 & 0.0 & 3.17 \\
b-p-0 & & 90 & 34.0 & 302 & 0.6 & 3.17 \\
c-p-0 & Polypropylene fiber & 95 & 30.0 & 311 & 0.9 & 3.20 \\
d-p-0 & & 100 & 29.5 & 325 & 1.2 & 3.21 \\
e-s-0 & & 95 & 62.5 & 343 & 60.0 & 3.21 \\
f-s-0 & Steel fiber & 100 & 36.0 & 330 & 80.0 & 3.23 \\
g-s-0 & & 105 & 34.0 & 339 & 100.0 & 3.28 \\
\hline
\end{tabular}




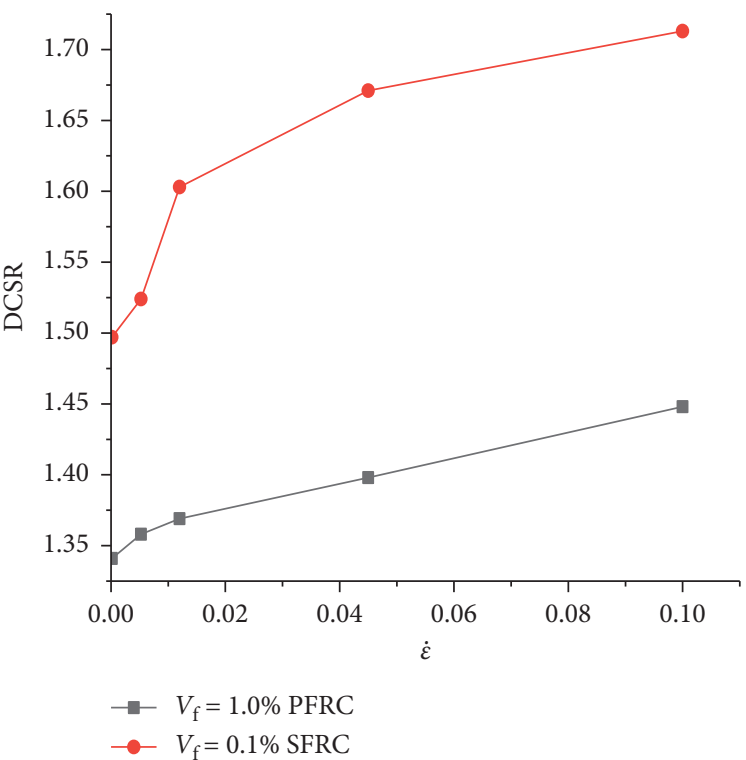

(a)

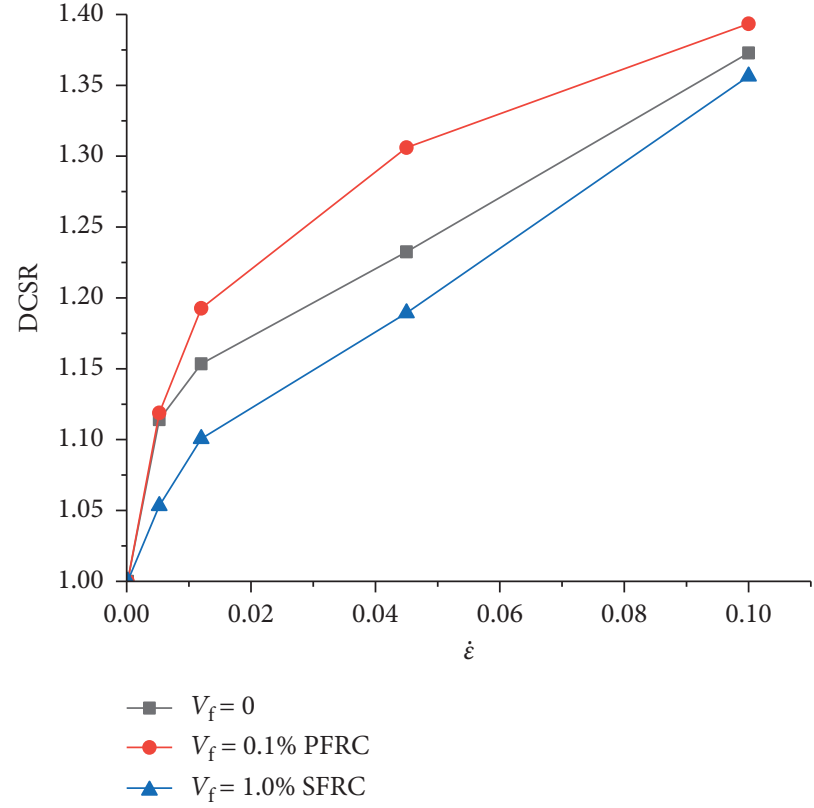

(b)

FIGURE 11: The variation of compressive strength with strain rate: (a) the variation of compressive strength ratio with strain rate relative to plain concrete; (b) the variation of compressive strength ratio with strain rate relative to FRC at $\dot{\varepsilon}=1.45 \times 10^{-4} / \mathrm{s}$.

\section{Comparative Analysis of PFRC and SFRC}

4.1. Comparative Analysis of Enhanced Performance. The dynamic compressive strength of PFRC with $0.1 \%$ and SFRC with $1.0 \%$ is chosen for comparison because the amount of steel fiber and polypropylene fiber is approximately the same in volume. Figure 11(a) shows that the compressive strength of concrete reinforced by steel fibers is significantly higher than that of polypropylene fibers. It is apparent from Figure 11(b) that both ordinary concrete and FRC show strain rate enhancement performance, but the strain rate enhancement performance of FRC is higher than that of ordinary concrete. To some extent, the increase in compressive strength of PFRC and SFRC at $\dot{\varepsilon}=5.24 \times 10^{-3} / \mathrm{s}$ is the same as that at $\dot{\varepsilon}=1.45 \times 10^{-4} / \mathrm{s}$. However, the increase in compressive strength of SFRC at $\dot{\varepsilon}=1.2 \times 10^{-2} / \mathrm{s}$, $\dot{\varepsilon}=4.5 \times 10^{-2} / \mathrm{s}$, and $\dot{\varepsilon}=1.0 \times 10^{-1} / \mathrm{s}$ is higher than that of PFRC, which is $4 \%, 7 \%$, and $3 \%$, respectively. Hence, the strain rate enhancement performance of SFRC is higher than that of PFRC.

4.2. Comparative Analysis of Toughening Properties. Toughening performance is one of the greatest advantages of FRC over ordinary concrete. It could be seen that the test results of PFRC and SFRC reflect the strengthening performance and the toughening performance of concrete. From Figure 12(a), it is evident that both kinds of FRC have obvious toughening properties, and the toughening effect increases with the increasing strain rate. However, the toughening effect of SFRC with $1.0 \%$ fiber content is always better than that of PFRC with $0.1 \%$ fiber content. As can be seen in Figure 12(b), the strain rate toughening performance of PFRC and SFRC is higher than that of ordinary concrete, and the strain rate toughening performance of SFRC with $1.0 \%$ fiber content is better than that of PFRC with $0.1 \%$ fiber content.

4.3. Economic Analysis. In the current practical application of FRC, the content of PFRC is $0.6 \mathrm{~kg} / \mathrm{m}^{3}$ to $1.5 \mathrm{~kg} / \mathrm{m}^{3}$, and the content of SFRC is $40 \mathrm{~kg} / \mathrm{m}^{3}$ to $200 \mathrm{~kg} / \mathrm{m}^{3}$. PFRC with content of $V_{\mathrm{f}}=0.1 \%$ and SFRC with content of $V_{\mathrm{f}}=1.0 \%$ are both more expensive than ordinary concrete, but the cost of SFRC is higher than that of PFRC. It could be seen from the previous analysis that the strength and toughness of PFRC with $0.1 \%$ fiber content at $\dot{\varepsilon}=1.45 \times 10^{-4} / \mathrm{s}$ are increased by $36.1 \%$ and $66.9 \%$, respectively, while those of SFRC are increased by $49.7 \%$ and $143.4 \%$, respectively. Moreover, the increase of strength and toughness of SFRC with $1.0 \%$ fiber content relative to ordinary concrete is 1.37 times and 2.143 times that of PFRC with $0.1 \%$ fiber content, respectively, while the cost increase of SFRC is about 55 times that of PFRC relative ordinary concrete. Therefore, polypropylene fiber is more suitable for concrete engineering than steel fiber.

4.4. Dynamic Constitutive Model of FRC. As shown above, the strain rate and fiber content both significantly affect stress-strain response of FRC. The underlying mechanisms are explained using damage mechanics. According to this theory, the main motivation behind nonlinear behavior of concrete is the generation, development, and concentration of microcracks, which is noted as damage [26]. Once concrete is under loading, microcracks initialize and develop. This causes the decrease of mechanical properties and 


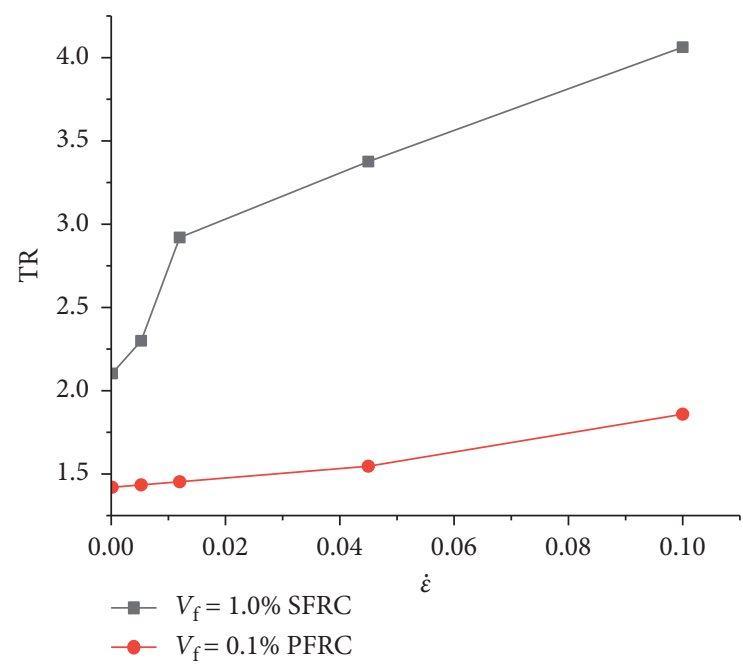

(a)

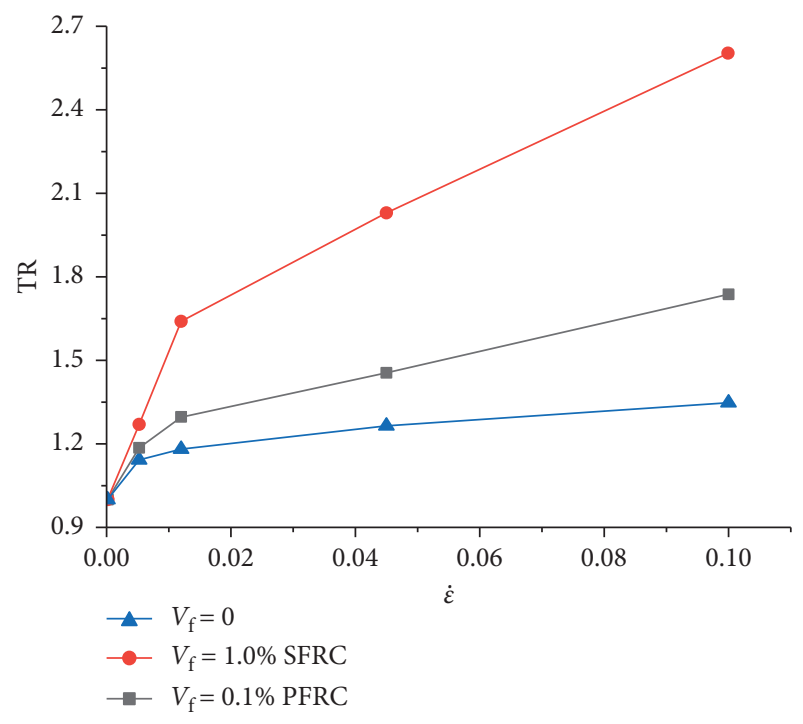

(b)

FIGURE 12: The variation of toughness ratio with strain rate: (a) the variation of toughness ratio with strain rate relative to plain concrete; (b) the variation of toughness ratio with strain rate relative to FRC at $\dot{\varepsilon}=1.45 \times 10^{-4} / \mathrm{s}$.

TABLE 7: Damage parameters of PFRC.

\begin{tabular}{lccc}
\hline Specimen number & $\dot{\varepsilon}(/ s)$ & $m$ & $a \times 10^{-3}$ \\
\hline a-n-1 & $1.45 \times 10^{-4}$ & 1.131 & 1.37 \\
a-n-2 & $5.24 \times 10^{-3}$ & 1.164 & 1.34 \\
a-n-3 & $1.20 \times 10^{-2}$ & 1.262 & 0.96 \\
a-n-4 & $4.50 \times 10^{-2}$ & 1.332 & 0.75 \\
a-n-5 & $1.00 \times 10^{-1}$ & 1.309 & 1.01 \\
b-p-1 & $1.45 \times 10^{-4}$ & 1.453 & 0.24 \\
b-p-2 & $5.24 \times 10^{-3}$ & 1.252 & 0.87 \\
b-p-3 & $1.20 \times 10^{-2}$ & 1.179 & 1.38 \\
b-p-4 & $4.50 \times 10^{-2}$ & 1.148 & 1.72 \\
b-p-5 & $1.00 \times 10^{-1}$ & 1.148 & 2.03 \\
c-p-1 & $1.45 \times 10^{-4}$ & 1.372 & 0.85 \\
c-p-2 & $5.24 \times 10^{-3}$ & 1.320 & 0.75 \\
c-p-3 & $1.20 \times 10^{-2}$ & 1.238 & 1.22 \\
c-p-4 & $4.50 \times 10^{-2}$ & 1.291 & 1.01 \\
c-p-5 & $1.00 \times 10^{-1}$ & 1.244 & 1.40 \\
d-p-1 & $1.45 \times 10^{-4}$ & 1.055 & 2.70 \\
d-p-2 & $5.24 \times 10^{-3}$ & 1.035 & 3.48 \\
d-p-3 & $1.20 \times 10^{-2}$ & 1.026 & 2.03 \\
d-p-4 & $4.50 \times 10^{-2}$ & 1.105 & 3.93 \\
d-p-5 & $1.00 \times 10^{-1}$ & 1.116 & 2.77 \\
\hline
\end{tabular}

Note: $\dot{\varepsilon}$ is the strain rate. $m$ and $a$ are material constants, which are related to the fiber content, the ratio of length to diameter, the strength of plain concrete, and the strain rate. $\varepsilon_{\mathrm{q}}$ is the threshold strain of material cumulative damage.

the complicated nonlinear behavior of concrete. To describe the weakening effect of damage inside material, we used a probability density function that obeys the Weibull distribution which was used to characterize the damage evolution of PFRC, namely, damage factor $D$ [21]. It can be defined as

$$
D= \begin{cases}0, & \varepsilon \leq \varepsilon_{\mathrm{q}}, \\ 1-e^{-\left(\left(\varepsilon-\varepsilon_{\mathrm{q}}\right)^{m} / a\right)}, & \varepsilon>\varepsilon_{\mathrm{q}},\end{cases}
$$

where $m$ and $a$ are material constants, which are related to the fiber content, and the strain rate $\varepsilon_{\mathrm{q}}$ is the threshold strain of material cumulative damage. $D$ represents the nonlinear behavior of concrete materials. Note that $D=0$ indicates that no damage exists inside material in the elastic phase and $D=1$ means the material completely loses its bearing capacity.

Therefore, this paper establishes a reasonable and appropriate constitutive relationship of FRC, as follows: 


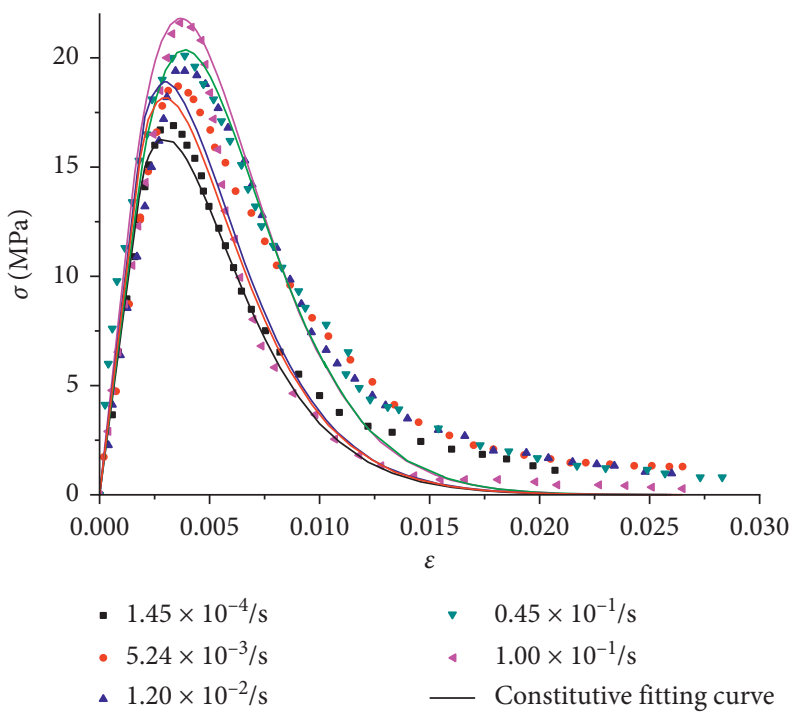

(a)

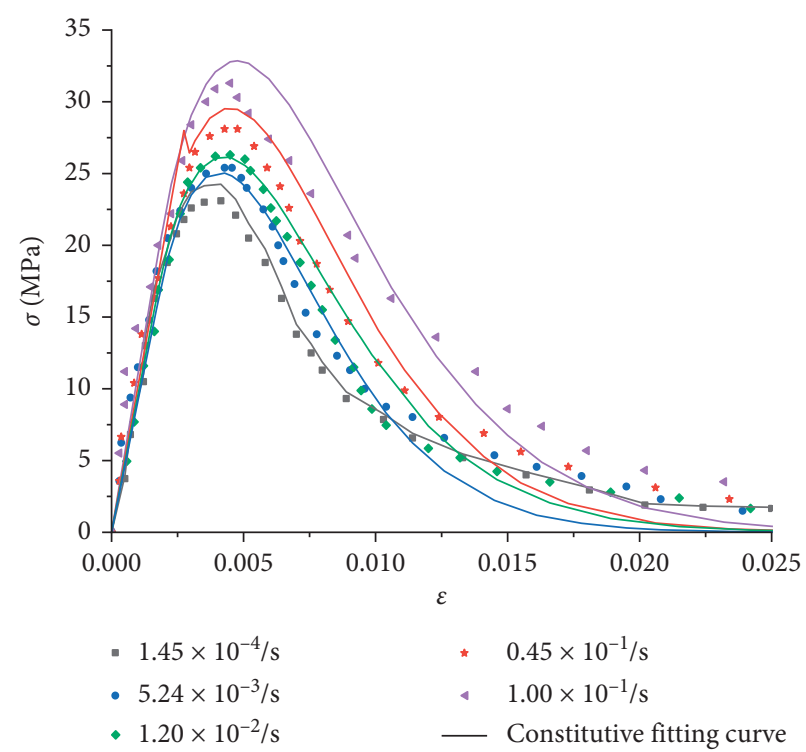

(c)

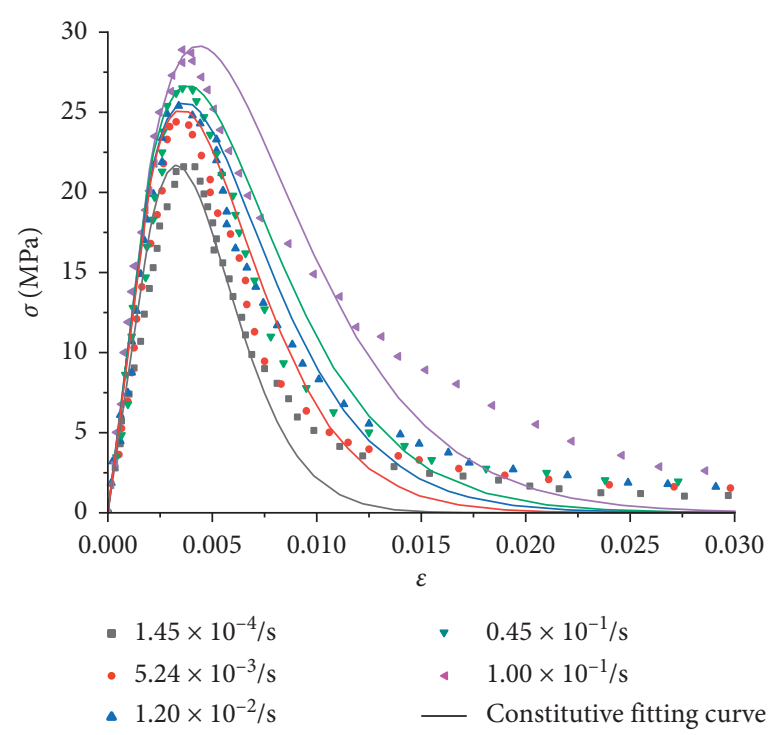

(b)

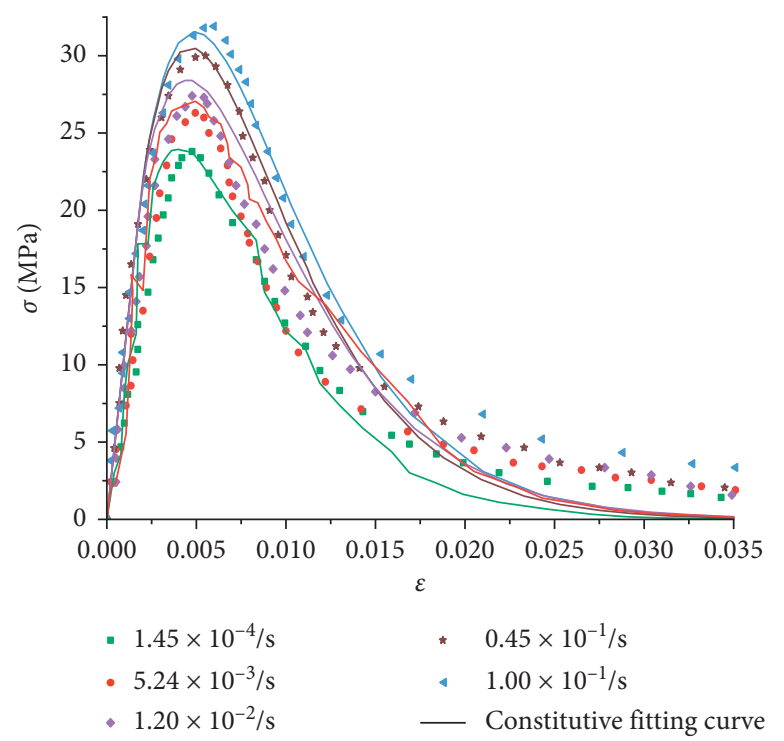

(d)

FIgure 13: Constitutive fitting of PFRC at different strain rates. (a) $V_{\mathrm{f}}=0$. (b) $V_{\mathrm{f}}=0.067 \%$. (c) $V_{\mathrm{f}}=0.10 \%$. (d) $V_{\mathrm{f}}=0.133 \%$.

$$
\sigma=(1-D) E_{0} \varepsilon K_{V_{\mathrm{f}}} K_{\dot{\varepsilon}}
$$

where $D$ represents the damage of FRC, $E_{0}$ represents Young's modulus of elasticity, $\varepsilon$ represents the strain of FRC, $K_{V_{\mathrm{f}}}$ represents the fiber reinforcement effect, and $K_{\dot{\varepsilon}}$ represents the strain rate enhancement effect.

For the reinforced concrete specimens with polypropylene fiber, the damage parameters $m$ and $a$ are obtained by fitting equation (7), which are summarized in Table 7. Considering the influence of fiber content $\left(V_{\mathrm{f}}\right)$ and strain rate $(\dot{\varepsilon})$ on flow stress, the following results could be obtained by fitting the experimental data in Figure 4:

$$
\begin{aligned}
K_{V_{\mathrm{f}}} & =1+524.9 V_{\mathrm{f}}-164002 V_{\mathrm{f}}^{2}, \\
K_{\dot{\varepsilon}} & =1.331+0.090 \lg \dot{\varepsilon} .
\end{aligned}
$$

As shown in Figure 13, it is apparent that the curves of PFRC fitted by the proposed damage constitutive model are in good agreement with the experimental data, especially in the rising stage but not very well in the decline stage. In addition, it can be seen from the fitting results that the dynamic elastic modulus of PFRC is closely related to the strain rate and increases with the increasing strain rate. As can be seen from Table 7 that $m$ and $\varepsilon_{\mathrm{q}}$ increase while $a$ decreases with the increasing strain rate. More specifically, it is apparent from equation (7) that $m$ has a more important effect on $D$ of PFRC than $a$, and $D$ increases with the increase of $m$. This means the development speed of damage factor $D$ of PFRC slows down as the strain rate increases.

For the reinforced concrete specimens with steel fiber, the damage parameters $m$ and $a$ are obtained by fitting equation (7), which are summarized in Table 8. Considering 
TAble 8: Damage parameters of SFRC.

\begin{tabular}{lccc}
\hline Specimen number & $\dot{\varepsilon}(/ s)$ & $m$ & $a \times 10^{-3}$ \\
\hline a-n-1 & $1.45 \times 10^{-4}$ & 1.131 & 1.37 \\
a-n-2 & $5.24 \times 10^{-3}$ & 1.164 & 1.34 \\
a-n-3 & $1.20 \times 10^{-2}$ & 1.262 & 0.96 \\
a-n-4 & $4.50 \times 10^{-2}$ & 1.332 & 0.75 \\
a-n-5 & $1.00 \times 10^{-1}$ & 1.309 & 1.01 \\
e-s-1 & $1.45 \times 10^{-4}$ & 1.381 & 0.44 \\
e-s-2 & $5.24 \times 10^{-3}$ & 1.392 & 0.54 \\
e-s-3 & $1.20 \times 10^{-2}$ & 1.440 & 0.48 \\
e-s-4 & $4.50 \times 10^{-2}$ & 1.498 & 0.46 \\
e-s-5 & $1.00 \times 10^{-1}$ & 1.387 & 0.97 \\
f-s-1 & $1.45 \times 10^{-4}$ & 0.991 & 5.85 \\
f-s-2 & $5.24 \times 10^{-3}$ & 1.021 & 5.56 \\
f-s-3 & $1.20 \times 10^{-2}$ & 1.141 & 3.41 \\
f-s-4 & $4.50 \times 10^{-2}$ & 1.248 & 2.55 \\
f-s-5 & $1.00 \times 10^{-1}$ & 1.176 & 3.39 \\
g-s-1 & $1.45 \times 10^{-4}$ & 1.132 & 2.95 \\
g-s-2 & $5.24 \times 10^{-3}$ & 1.118 & 2.23 \\
g-s-3 & $1.20 \times 10^{-2}$ & 0.937 & 3.47 \\
g-s-4 & $4.50 \times 10^{-2}$ & 0.993 & 10.79 \\
g-s-5 & $1.00 \times 10^{-1}$ & 0.948 & 9.26 \\
\hline
\end{tabular}

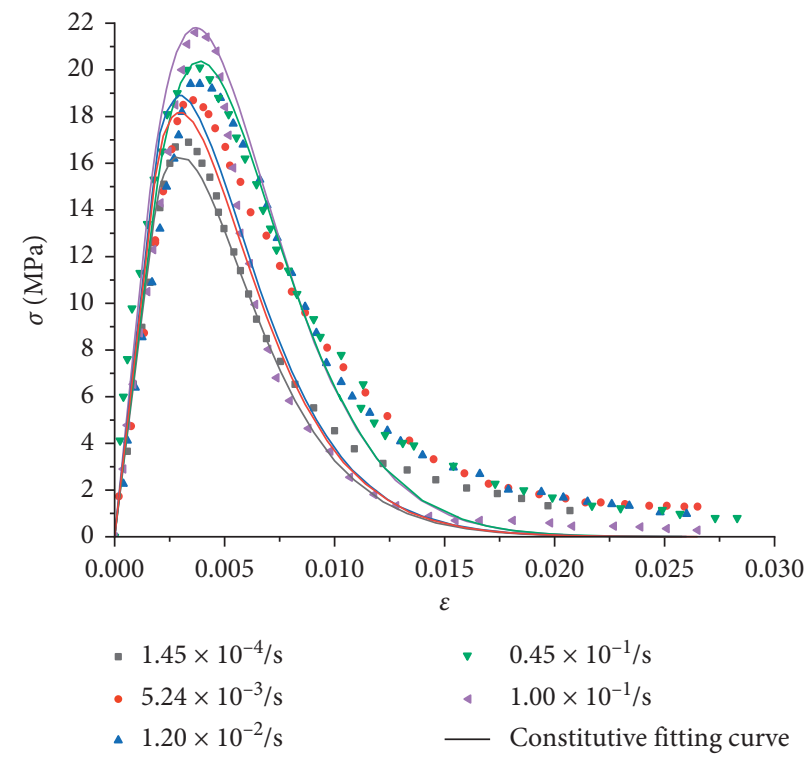

(a)

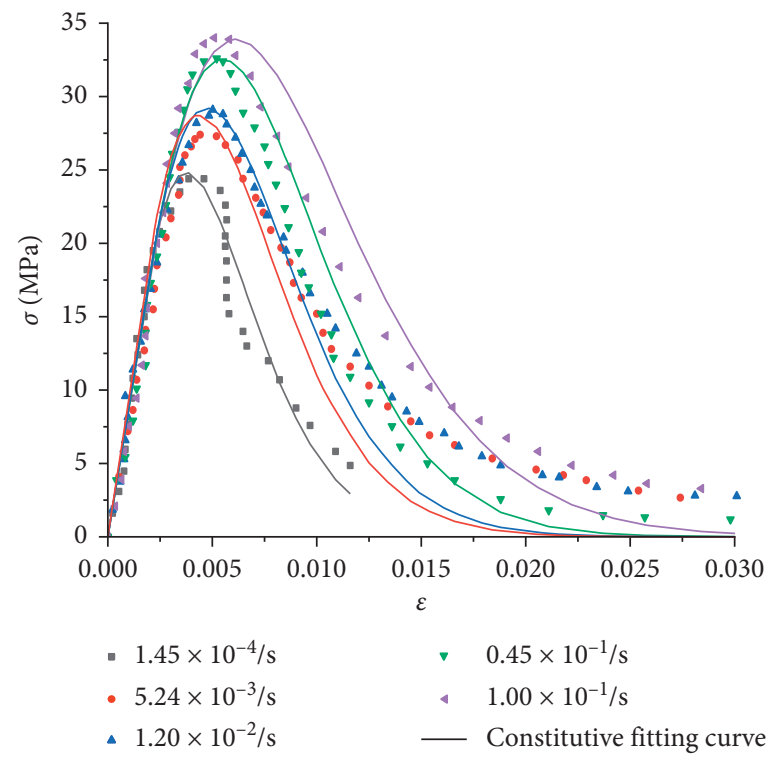

(b)

FIgURE 14: Continued. 


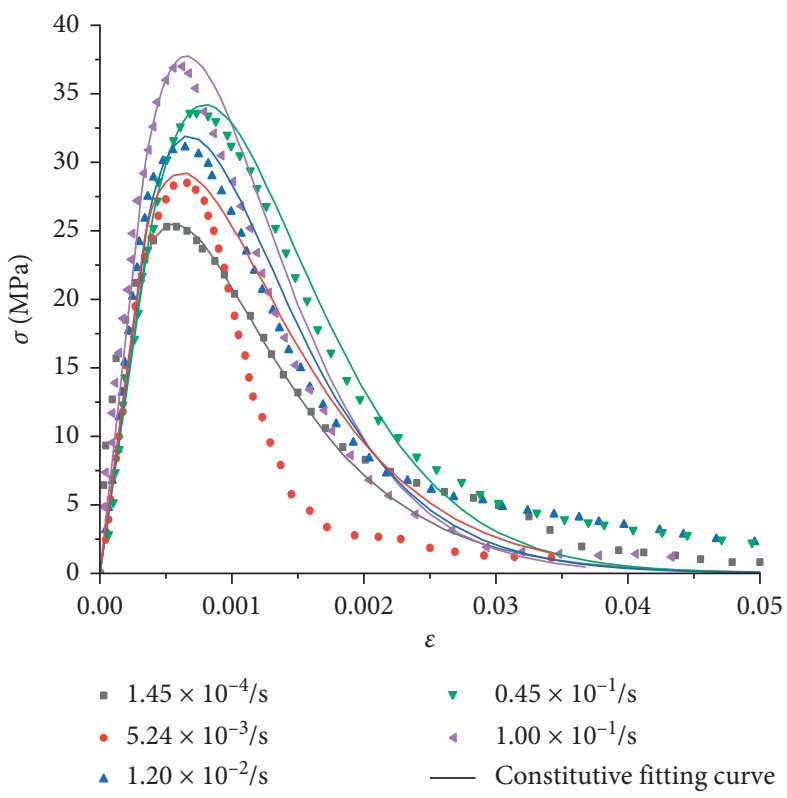

(c)

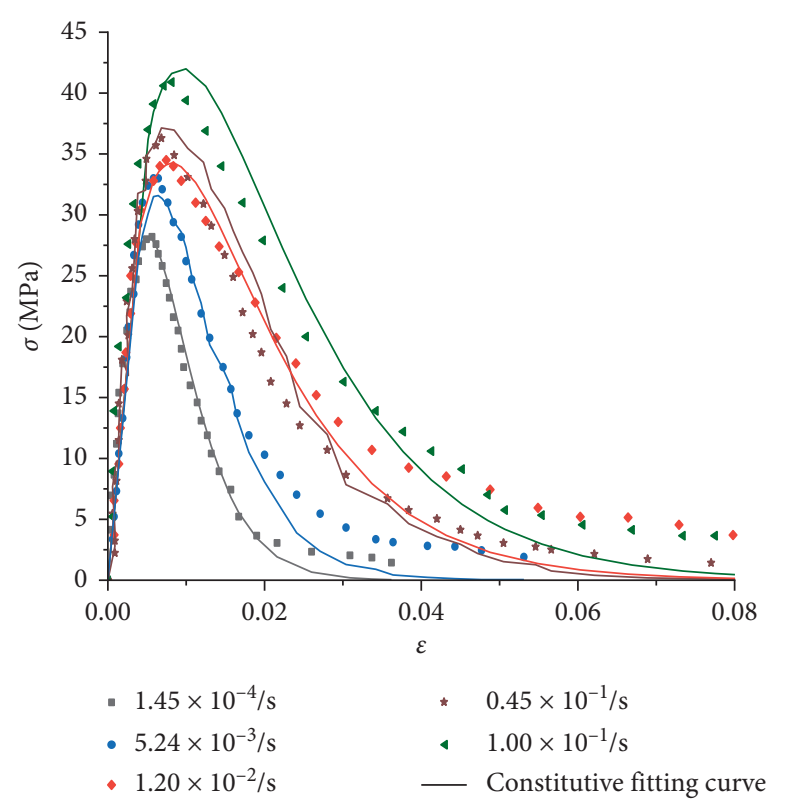

(d)

Figure 14: Constitutive fitting of SFRC at different strain rates.

. (a) $V_{\mathrm{f}}=0$. (b) $V_{\mathrm{f}}=0.75 \%$. (c) $V_{\mathrm{f}}=1.00 \%$. (d) $V_{\mathrm{f}}=1.25 \%$.

the influence curves of fiber content $\left(V_{\mathrm{f}}\right)$ and strain rate $(\dot{\varepsilon})$ on flow stress, the following results could be also obtained by fitting the experimental data in Figure 4:

$$
\begin{aligned}
K_{V_{\mathrm{f}}} & =47.83189 \ln \left(V_{\mathrm{f}}+0.90737\right)+5.65857, \\
K_{\dot{\varepsilon}} & =1.3312+0.0904 \lg \dot{\varepsilon} .
\end{aligned}
$$

It can be seen from Figure 14 that the curves of SFRC fitted by the proposed damage constitutive model are in good agreement with the experimental data in the rising stage, but not very well in the decline stage. Moreover, from the fitting results, we can see that the dynamic elastic modulus of SFRC, $m, \varepsilon_{\mathrm{q}}, a$, and $D$ show a similar law to that of PFRC, indicating the damage parameters of FRC are independent of the fiber type.

\section{Conclusions}

The effect of fiber content and strain rate on the mechanical performance of FRC was investigated by using the electrohydraulic servo loading method. In addition, this paper also studied the dynamic constitutive relationship for concrete under uniaxial compression based on damage mechanics. Eventually, the following conclusions can be obtained:

(1) In general, the dynamic mechanical performance of concrete is improved with the increase of strain rate and appropriate fiber content. The experimental results show that FRC is a strain-rate-dependent material, and both polypropylene and steel fibers have obvious strengthening and toughening effect on concrete strength. The parameters of dynamic mechanical performance, such as peak stress, peak strain, and toughness, are affected by strain rate and are improved along with the strain rate.
(2) When $\dot{\varepsilon}=1.45 \times 10^{-4} / \mathrm{s}$, the peak stress, peak strain, and toughness of PFRC are $27.8 \% \sim 40.9 \%, 8 \%$ $41.7 \%$, and $5.6 \% \sim 113 \%$ higher than that of plain concrete. In addition, the peak stress, peak strain, and toughness of SFRC are $44.4 \% \sim 76.5 \%, 36.9 \%$ $68 \%$, and $19.7 \% \sim 126.5 \%$, higher than that of plain concrete. However, as far as the economy of FRC is concerned, polypropylene fiber is more suitable for concrete engineering than steel fiber.

(3) The parameters of dynamic mechanical properties, such as the dynamic compressive strength, DIF, peak strain, and peak toughness, are affected by strain rate and are improved along with the strain rate under fast loading. DIF and $\lg \dot{\varepsilon}$ show approximately linear correlation, and the corresponding fitting formulas for each group are given in Table 5. Furthermore, it is found that the peak strain and toughness are quadratic functions with $\lg \dot{\varepsilon}$, and the corresponding fitting formulas are also given, respectively, as shown in Table 5.

(4) The stress-strain curves obtained from the test agree well with the curves fitted by the proposed damage dynamic constitutive model under fast loading and the damage constitutive model including fiber enhancement effect and strain rate enhancement effect. This shows that the modified model can well describe the dynamic behavior of FRC subjected to fast loading. Besides, the damage evolution of microcracks inside concrete could be reflected from the derived parameters $(D)$.

\section{Data Availability}

The data used to support the findings of this study are available from the corresponding author upon request. 


\section{Disclosure}

Jie Huang and Yi Zhang contributed equally to this study as co-first authors.

\section{Conflicts of Interest}

The authors declare that there are no conflicts of interest regarding the publication of this paper.

\section{Acknowledgments}

The authors would like to express their gratitude to Nianlin Zhang for carrying out the excellent experiment of FRC specimens and giving the complete experimental data. The authors would also like to thank the members of the HIT 504 office for their selfless help and useful suggestions.

\section{References}

[1] Ş. Yazıc1, G. İnan, and V. Tabak, "Effect of aspect ratio and volume fraction of steel fiber on the mechanical properties of SFRC," Construction and Building Materials, vol. 21, no. 6, pp. 1250-1253, 2007.

[2] K. L. Ahn, S. J. Jang, Y. J. Yun, D. G. Yu, and H. D. Yun, "Effect of fiber volume fraction on compressive and flexural properties of high-strength steel fiber reinforced concrete," Applied Mechanics and Materials, vol. 597, pp. 296-299, 2014.

[3] P. Archana, A. N. Nayak, S. R. Nayak, and H. Vaddar, "Study of strength of polypropylene fiber reinforced concrete," International Journal of Engineering \& Technical Research, vol. 6, no. 6, pp. 8-11, 2017.

[4] J. Broda, "Application of polypropylene fibrillated fibres for reinforcement of concrete and cement mortars," High Performance Concrete Technology and Applications, pp. 189-204, 2016.

[5] N. Abdelhamid and S. Belattar, "Improvement of the mechanical properties of concretes and mortars by addition of polypropylene," Journal of Engineering Technology, vol. 6, pp. 139-154, 2017.

[6] L. Soufeiani, S. N. Raman, M. Z. B. Jumaat, U. J. Alengaram, G. Ghadyani, and P. Mendis, "Influences of the volume fraction and shape of steel fibers on fiber-reinforced concrete subjected to dynamic loading-a review," Engineering Structures, vol. 124, pp. 405-417, 2016.

[7] C. Redon and J. L. Chermant, "Damage mechanics applied to concrete reinforced with amorphous cast iron fibers, concrete subjected to compression," Cement and Concrete Composites, vol. 21, no. 3, pp. 197-204, 2007.

[8] J. A. O. Barros and J. A. Figueiras, "Flexural behavior of SFRC: testing and modeling," Journal of Materials in Civil Engineering, vol. 11, no. 4, pp. 331-339, 1999.

[9] D. Y. Figueiras, H. T. Zhu, and Z. Tang, "Shear strength of steel fiber reinforced high strength concrete," Journal of the Chinese Ceramic Society, vol. 33, no. 1, pp. 82-86, 2005.

[10] A. M. Alhozaimy, P. Soroushian, and F. Mirza, "Mechanical properties of polypropylene fiber reinforced concrete and the effects of pozzolanic materials," Cement and Concrete Composites, vol. 18, no. 2, pp. 85-92, 1996.

[11] G. D. Manolis and P. J. Gateis, "Dynamic properties of polypropylene fiber-reinforced concrete slabs," Cement and Concrete Composites, vol. 19, no. 4, pp. 341-349, 1997.
[12] C. Cao and J. B. Liu, "Study on the influence of polypropylene fibers on the dynamic characteristics of concrete," Concrete, no. 5, pp. 43-45, 2000.

[13] N. Banthia and N. Nandakumar, "Crack growth resistance of concrete reinforced with a low volume fraction of polymericm fiber," Journal of Materials Science Letters, vol. 20, no. 17, pp. 1651-1653, 2001.

[14] D. Y. Chen and K. F. Tan, "Properties of polypropylene fiber reinforced concrete," China Concrete and Cement Products, no. 3, pp. 38-40, 2004.

[15] P. Rossi, A. Arca, and E. Parant, "Bending and compressive behaviors of a new cement composite," Cement and Concrete Research, vol. 35, no. 1, pp. 27-33, 2001.

[16] S. H. Yan, Z. C. Li, M. Y. Wang, and F. L. Yin, "Experimental study on impact compression characteristics of high strength steel fiber reinforced concrete," Explosion and Shock Waves, vol. 22, no. 3, pp. 237-241, 2002.

[17] X. T. Wu, S. S. Hu, D. X. Chen, and Z. Q. Yu, "Experimental study on impact compression of steel fiber reinforced high strength concrete," Explosion and Shock Waves, vol. 25, no. 2, pp. 125-131, 2005.

[18] J. S. Hu, X. M. Yang, Z. S. Zhou, and D. G. Tang, "Experimental study on toughening properties of steel fiber reinforced concrete and polypropylene fiber reinforced concrete under impact load," Journal of Building Structures, vol. 26, no. 2, pp. 101-105, 2005.

[19] Z. Xu, H. Hao, and H. N. Li, "Experimental study of dynamic compressive properties of fibre reinforced concrete material with different fibres," Materials \& Design, vol. 33, pp. 42-55, 2012.

[20] S. C. Li, R. Y. Huang, L. Li, and Y. H. Chen, "Study on toughening effect of steel fiber reinforced concrete," Concrete, vol. 12, pp. 63-74, 2017.

[21] Y. L. Dong, P. Xie, and S. P. Li, "Study on the constitutive model of compressive damage mechanics of concrete," Engineering Mechanics, vol. 13, no. 1, pp. 44-53, 1996.

[22] R. J. Shang, Study on dynamic constitutive behavior of concrete, Ph.D. thesis, Dalian University of Technology, Dalian, Liaoning, 1994.

[23] Chinese Standard GB/T 50081, Standard for Test Method of Mechanical Properties on Ordinary Concrete, China Architecture and Building Press, Beijing, China, 2003, in Chinese.

[24] J. W. Tedesco and C. A. Ross, "Strain-rate-dependent constitutive equations for concrete," Journal of Pressure Vessel Technology, vol. 120, no. 4, pp. 398-405, 1998.

[25] J. Wongpa, K. Kiattikomol, C. Jaturapitakkul, and P. Chindaprasirt, "Compressive strength, modulus of elasticity, and water permeability of inorganic polymer concrete," Materials \& Design, vol. 31, no. 10, pp. 4748-4754, 2010.

[26] K. E. Løland, "Continuous damage model for load-response estimation of concrete," Cement and Concrete Research, vol. 10, no. 3, pp. 395-402, 1980. 